Article

\title{
Smart Farming Technology Trends: Economic and Environmental Effects, Labor Impact, and Adoption Readiness
}

\author{
Athanasios T. Balafoutis ${ }^{1, *}$, Frits K. Van Evert ${ }^{2} \mathbb{D}$ and Spyros Fountas ${ }^{3}$ \\ 1 Institute of Bio-Economy \& Agro-Technology, Centre of Research \& Technology Hellas, Dimarchou \\ Georgiadou 118, 38333 Volos, Greece \\ 2 Agrosystems Research, Wageningen University \& Research, P.O. Box 16, 6700 AA Wageningen, \\ The Netherlands; frits.vanevert@wur.nl \\ 3 Department of Natural Resources Management and Agricultural Engineering, Agricultural University of \\ Athens, 11855 Athens, Greece; sfountas@aua.gr \\ * Correspondence: a.balafoutis@certh.gr; Tel.: +30-2311-257-651
}

Received: 18 February 2020; Accepted: 18 May 2020; Published: 21 May 2020

\begin{abstract}
Farming faces challenges that increase the adverse effects on farms' economics, labor, and the environment. Smart farming technologies (SFTs) are expected to assist in reverting this situation. In this work, 1064 SFTs were derived from scientific papers, research projects, and industrial products. They were classified by technology readiness level (TRL), typology, and field operation, and they were assessed for their economic, environmental, and labor impact, as well as their adoption readiness from end-users. It was shown that scientific articles dealt with SFTs of lower TRL than research projects. In scientific articles, researchers investigated mostly recording technologies, while, in research projects, they focused primarily on farm management information systems and robotic/automation systems. Scouting technologies were the main SFT type in scientific papers and research projects, but variable rate application technologies were mostly located in commercial products. In scientific papers, there was limited analysis of economic, environmental, and labor impact of the SFTs under investigation, while, in research projects, these impacts were studied thoroughly. Further, in commercial SFTs, the focus was on economic impact and less on labor and environmental issues. With respect to adoption readiness, it was found that all of the factors to facilitate SFT adoption became more positive moving from SFTs in scientific papers to fully functional commercial SFTs, indicating that SFTs reach the market when most of these factors are addressed for the benefit of the farmers. This SFT analysis is expected to inform researchers on adapting their research, as well as help policy-makers adjust their strategy toward digitized agriculture adoption and farmers with the current situation and future trends of SFTs.
\end{abstract}

Keywords: smart farming technologies; recording; reacting; guiding; farm management information system; agricultural robots; automated systems

\section{Introduction}

Agricultural performance in terms of productivity led farming practices after the Green Revolution of the 1950s, with limited attention paid to the respective impact on sustainability. However, conventional farming practices are at a point where agricultural inputs are overused, labor is no longer in abundance, and the energy demand is continuously increasing [1]. New opportunities are emerging in farming, as a result of the rapid development of communication networks and the availability of a wide range of new remote, proximal, and contact sensors [2-6]. In the agricultural context, these technologies help capture and transmit geo-localized real-time information at low 
cost [7-10]. Once gathered, processed, and analyzed, these data can assist in determining the state of the agro-environment (e.g., soil, crop, and climate) and, when combined with agro-climatic and economic models, technical interventions can be applied at the field level by either conventional means or automated/robotized solutions [11].

All these aspects are under the concept named "smart farming" that represents the application of modern information and communication technologies (ICT) into agriculture [12-14]. These include variable rate applicators [15-17], Internet of things (IoT) [18,19], geo-positioning systems [20,21], big data [22-24], unmanned aerial vehicles (UAVs, drones) [18,25], automated systems, and robotics [26,27]. Smart farming is based on a precise and resource-efficient approach and attempts to achieve higher efficiency on agricultural goods production with increased quality in a sustainable basis [28]. However, from the farmer's point of view, smart farming should provide added value in the form of more accurate and timely decision-making and/or more efficient exploitation operations and management [29].

Smart farming technologies (SFTs) can be divided into three main categories: farm management information systems (FMIS), precision agriculture (PA) systems, and agricultural automation and robotics. FMISs represent mainly software systems for collecting, processing, storing, and disseminating data in the form required to carry out a farm's operations and functions. Significant research work was carried out in this area in the last 20 years [30-33] and this development assisted in having many commercial products already on the market that, in many cases, show significant economic, environmental, and social benefits [28].

PA refers to the farming management concept aimed at optimizing input use based on recording technologies to observe and measure inter- and intra-field spatial and temporal variability in crops, aiming to improve economic returns and reduce environmental impact [34]. PA is able to increase input efficiency for maintaining or even increasing production rate [35-37], using remote sensing technologies for data gathering with either satellite platforms for space imagery [38-40] or aircrafts/UAVs for aerial applications [41-43], combined use of sensors for ground data acquisition [44], wireless networks for interconnecting them $[4,10,45,46]$, geospatial data analytics coming from different sources [47], decision support systems (DSSs) for optimized farming decision-making [48,49], and others.

Reacting technologies are based on agricultural automation and robotics that are separate, but closely related ICT sectors. In the case of open-field agriculture, they are interconnected to cover the process of applying automatic control, artificial intelligence techniques, and robotic platforms at all levels of agricultural production. Automation technologies in agriculture found high research interest with machine learning being thoroughly used for agricultural purposes [50-52], as well as computer vision and artificial intelligence [53,54], three-dimensional (3D) imagery [55], and navigation systems for off-road agricultural vehicles [56]. Based on these developments and on the industrial robotic state of the art, agricultural robots of all types were applied in recent years [26,57-59] with specific tasks, such as weed control [60], harvesting [61], etc.

Attention toward smart farming is growing rapidly, and several studies of the current status of SFT development and adoption rate among farmers worldwide were released. The most known, due to its continuous bi-annual release from 1997 until today, is the CropLife/Purdue Precision Ag Survey that deals with adoption rates of certain SFTs in the United States (US) and Canada, based on retail crop input dealers regarding their smart farming services. The last version (2019) [62] showed the increasing use of data for crop management decisions, with sensing technology services (soil sampling, satellite/UAV imaging, yield mapping) and variable rate services being significantly increased in comparison to the previous edition (2017), presenting the continuous SFT adoption increment in the US.

In Europe, where smart farming is less diffused than North America, SFT uptake is less explored, while most studies are country-specific [63]. However, recent SFT adoption research was conducted in different European countries to also observe geographical and cultural causes of reduced adoption rates [29,63,64]. Particularly, Barnes et al. (2019a) [63] considered machine guidance and variable rate nitrogen technologies as the most significant SFTs for arable farming and conducted an empirical examination of uptake in five European countries. They showed that farm size and income reflect the 
most important barriers to adoption for all countries under investigation; furthermore, in countries with small farms of low income, subsidy and taxation were considered the main positive drivers of SFT uptake. Barnes et al. (2019b) [64] also identified incentives for SFTs to be adopted in Europe using data from the same five countries as in Reference [63], and it was found that current SFT adopters are divergent from non-adopters, while the first adopters are influenced by economic and informational interventions. Increasing adoption is constrained by skepticism toward economic returns and that European Union (EU) policy does not recognize complexity across domains to enable uptake. Kernecker et al. (2020) [29] also worked on the adoption of technological innovations in agriculture by conducting a survey in seven European countries and in four cropping systems, and they showed that adoption increases with farm size in arable farms. Farmers perceive SFT as useful, but they are still not convinced of SFT potential. On the other hand, experts seem to be more convinced of SFT assets and expect a lot from SFT future development. Country specificities should be considered to improve SFT diffusion.

Even if adoption rates can be increased through optimization of SFT results and related policies and incentives, SFTs comes with the risk of rebound effects of their use in agricultural practices. This is because, even if smart farming is expected to considerably contribute to environmental and resource protection (as stated above using PA techniques), the occurrence of potential rebound effects for agricultural land, water, fertilizers, and plant protection products is highly probable [65-67].

It is evident that smart farming evolves technologically at a fast pace in both research and market domains, but its adoption from end-users does not follow the same footsteps. If an evaluation of the promising positive impact of SFTs accompanied by an adoption readiness analysis would be available, then the uptake of such technologies would possibly increase. Hence, a thorough assessment and comparison of SFTs from research (scientific papers), innovation (research projects), and market (commercial products) could assist in better understanding the evolution of SFTs and how this evolution affects factors of adoption readiness and related economic, environmental, and labor aspects within a farm. Based on this need, the objective of this study was (i) to map the existing research and commercial SFTs with regard to their technological readiness level, type, and the field operation they are used for; (ii) to identify the ease of SFT adoption; and (iii) to provide the main impacts of SFTs on farm economics, environment, and labor. This work is expected to contribute to the literature with a global perspective of various SFTs developed from research to innovation and then to the market, as well as show the differences in their impact and adoption readiness.

\section{Materials and Methods}

This work focuses on open-field production; hence, we considered SFTs used in arable (including fodder production) and horticultural (fruit and vegetable production) farming. A review of such SFTs was conducted based on scientific literature, current and past EU research projects, and commercially available products. The economic and environmental challenges that SFTs face were determined by a set of key performance indicators (KPIs) (Section 2.1). For the selection of the SFTs, a systematic search procedure was developed for scientific papers, research projects, and commercial products (Section 2.2). Finally, information about the identified SFTs was collected by developing a questionnaire to record data for each SFT's adoption readiness and its performance regarding the selected KPIs (Section 2.3).

\subsection{Key Performance Indicators for Open Field Production}

Several authors proposed grouping indicators to measure the performance of agricultural systems. In a study in the United Kingdom (UK), indicator clusters (e.g., biodiversity, energy, value chain) were defined, with measurable parameters for each cluster (e.g., number of species on the farm, energy balance, total value of production) [68]. In another study, the literature on agricultural sustainability was surveyed, and indicators were identified and grouped in a three-level hierarchy [69]. An in-depth review of indicator construction is also available [70]. Indicator sets were also proposed by public organizations, such as the European Environmental Agency (EEA) [71] and the Organization for 
Economic Co-operation and Development (OECD) [72], as well as private organizations, such as The Sustainability Consortium (TSC) [73] and Global Reporting Initiative (GRI) [74]. All these indicator sets are different and have slightly different purposes. There is not one single set of indicators that suits our current purpose better than all the others. We used the published indicator sets for our study.

We examined the published indicators and derived challenges in agriculture that could be possibly addressed by SFTs. In Table 1, these challenges are listed along with SFTs that can be used to address them.

Table 1. Challenges identified in open-field farming accompanied by relevant smart farming technologies (SFTs) that could address them. DSS—-decision support system; FMIS—farm management information system; VRA—variable rate application; RFID—radio frequency identification; QR Quick Response.

\begin{tabular}{|c|c|}
\hline Challenge & Relevant Smart Farming Technologies \\
\hline $\begin{array}{l}\text { Resource efficiency (e.g., water, nutrients, pesticides, } \\
\text { labor) }\end{array}$ & $\begin{array}{ll}\text { - } & \text { sensors and networks } \\
\text { - } & \text { big data analytic tools } \\
\text { - } & \text { DSS } \\
\text { - } & \text { FMIS } \\
\text { - } & \text { intelligent water application systems } \\
\text { - } & \text { VRA fertilization/pesticides systems } \\
\text { - } & \text { RFID tags }\end{array}$ \\
\hline Management/prevention of diseases, weeds, etc. & $\begin{array}{ll}\text { - } & \text { early warning sensors and networks } \\
\text { - } & \text { specific farm machines } \\
\text { - } & \text { FMIS } \\
\text { - } & \text { DSS for infestation management } \\
\text { - } & \text { VRA spraying system }\end{array}$ \\
\hline $\begin{array}{l}\text { Risk management (e.g., food safety, pesticide residue } \\
\text { elimination and emission of agro-chemicals, etc.) }\end{array}$ & $\begin{array}{l}\text { - } \quad \text { sensors (e.g., weather station, } \\
\text { multispectral cameras, thermal cameras, } \\
\text { etc.) } \\
\text { - } \quad \text { traceability technology } \\
\text { - barcodes, QR codes, RFID } \\
\text { - } \quad \text { real-time recording systems }\end{array}$ \\
\hline $\begin{array}{l}\text { Compliance with legislation and standards (greening } \\
\text { of CAP; regulations on soil management, pesticide, } \\
\text { fertilizer, and water use) }\end{array}$ & $\begin{array}{l}\text { - } \quad \text { recording technologies } \\
\text { web-based, open, and interoperable } \\
\text { standards for end-to-end tracking } \\
\text { systems }\end{array}$ \\
\hline $\begin{array}{l}\text { Collaboration across the supply chain (supply chain } \\
\text { of companies and processors) }\end{array}$ & $\begin{array}{ll}\text { - } & \text { smart traceability system } \\
\text { - } & \text { smart logistics system } \\
\text { - } & \text { various analytical tools }\end{array}$ \\
\hline
\end{tabular}

We examined the published indicators to create a list of KPIs to be used for assessing the impact of SFTs in terms of three main issues associated with agricultural systems that are of high importance for end-users and the general public: farm economics, the environment, and labor within the farm (Table 2). The definition of each KPI and the reasoning for including them are given in Table 2. These KPIs are, in many cases, interconnected and might also have an impact on each other. 
Table 2. Key performance indicators (KPIs) combined with their description and the reasoning for their inclusion to assess the impact of smart farming technologies (SFTs) in open-field farming, regarding farm economics, environment, and labor within the farm.

\begin{tabular}{|c|c|c|c|}
\hline $\mathrm{A} / \mathrm{A}$ & $\begin{array}{l}\text { Key Performance } \\
\text { Indicator }\end{array}$ & $\begin{array}{l}\text { Description of the KPI in Relation } \\
\text { to the Specific Impact Category }\end{array}$ & $\begin{array}{l}\text { Reasoning to Be Selected as Significant KPI in } \\
\text { the Specific Impact Category }\end{array}$ \\
\hline & \multicolumn{3}{|l|}{ Farm Economics } \\
\hline 1 & Productivity & $\begin{array}{l}\text { Ratio of a volume measure of output } \\
\text { to a volume measure of input use in } \\
\text { farm production [75] }\end{array}$ & $\begin{array}{l}\text { It is an index to express the optimization of the } \\
\text { agricultural practices of a farm through SFT use, } \\
\text { which reflects farm economics }\end{array}$ \\
\hline 2 & Quality of product & $\begin{array}{l}\text { Qualitative features of agricultural } \\
\text { products (e.g., intact, sound, clean, } \\
\text { free of pests, fresh appearance, normal } \\
\text { and sufficient physiological and } \\
\text { morphological development, maturity, } \\
\text { firmness, free of decay affecting } \\
\text { edibility, absence of defects) [76] }\end{array}$ & $\begin{array}{l}\text { The influence of SFTs on the product quality } \\
\text { could increase product value }\end{array}$ \\
\hline 3 & Revenue & $\begin{array}{l}\text { Income of a farm from its normal } \\
\text { business activities, usually from the } \\
\text { sales of agricultural goods to } \\
\text { customers [77] }\end{array}$ & $\begin{array}{l}\text { Revenue is crucial for the viability of farms, and } \\
\text { SFTs could assist in its increase by optimizing } \\
\text { production and quality }\end{array}$ \\
\hline 4 & Input costs & $\begin{array}{l}\text { Cost of inputs (e.g., seeds, fertilizers, } \\
\text { pesticides, fuel, irrigation water) [78] }\end{array}$ & $\begin{array}{l}\text { The main role of SFTs is the optimization of } \\
\text { inputs that reflect cost reduction for a farm }\end{array}$ \\
\hline 5 & Variable costs & $\begin{array}{l}\text { Expenses that vary in direct } \\
\text { proportion to the quantity of output } \\
\text { (e.g., raw materials, packaging, labor) } \\
\text { [79] }\end{array}$ & $\begin{array}{l}\text { Reduction of all farm expenses employing } \\
\text { different kinds of SFTs can positively impact the } \\
\text { final income }\end{array}$ \\
\hline 6 & Crop wastage & $\begin{array}{l}\text { Crop that gets spilled or spoilt before } \\
\text { it reaches the market (e.g., fruits with } \\
\text { blots or blemish from pests, or of } \\
\text { irregular shape from abnormal } \\
\text { development) [80] }\end{array}$ & $\begin{array}{l}\text { SFTs could assist in better crop protection } \\
\text { schemes and selective harvesting reducing crop } \\
\text { wastage }\end{array}$ \\
\hline \multirow[t]{2}{*}{7} & Energy use & $\begin{array}{l}\text { Amount of energy that is used for all } \\
\text { needs of a farm [81] }\end{array}$ & $\begin{array}{l}\text { Optimized processes in the farm (e.g., tractor or } \\
\text { robot rooting, selective harvesting that reduces } \\
\text { storage needs, etc.) can reduce energy use and } \\
\text { the respective cost }\end{array}$ \\
\hline & \multicolumn{3}{|l|}{ Environment } \\
\hline 8 & Soil biodiversity & $\begin{array}{l}\text { The variation in soil life, from genes to } \\
\text { communities, and the ecological } \\
\text { complexes of which they are part, i.e., } \\
\text { from soil micro-habitats to landscapes } \\
\text { [82] }\end{array}$ & $\begin{array}{l}\text { Optimized crop production using SFTs (i.e., } \\
\text { minimizing field passes using auto-guidance) } \\
\text { could preserve soil biodiversity and } \\
\text { sustainability, allowing soil life conservation }\end{array}$ \\
\hline 9 & Biodiversity & $\begin{array}{l}\text { The number and types of plants and } \\
\text { animals that exist in a particular area } \\
\text { or in the world generally [83] }\end{array}$ & $\begin{array}{l}\text { Reduced biodiversity impact through } \\
\text { optimization of inputs (variable rate fertilization } \\
\text { or pesticide application) and spray drift } \\
\text { reduction using SFTs }\end{array}$ \\
\hline 10 & Fertilizer use & $\begin{array}{l}\text { Extent of fertilizer use in agricultural } \\
\text { production [84] }\end{array}$ & $\begin{array}{l}\text { Decreasing the fertilizer use applying SFTs } \\
\text { means that leaching to ground water or high soil } \\
\text { GHG emissions can be reduced }\end{array}$ \\
\hline 11 & Pesticide use & $\begin{array}{l}\text { Extent of pesticide use in agricultural } \\
\text { production [85] }\end{array}$ & $\begin{array}{l}\text { Pesticide use reduction employing SFTs can } \\
\text { provide less point and diffuse contamination of } \\
\text { non-crop areas }\end{array}$ \\
\hline 12 & Irrigation water use & $\begin{array}{l}\text { Water applied by an irrigation system } \\
\text { to sustain plant growth in agricultural } \\
\text { and horticultural practices [86] }\end{array}$ & $\begin{array}{l}\text { Optimizing water use with SFT application } \\
\text { would assist in maintaining water reserves and } \\
\text { reduce over-pumping }\end{array}$ \\
\hline
\end{tabular}


Table 2. Cont.

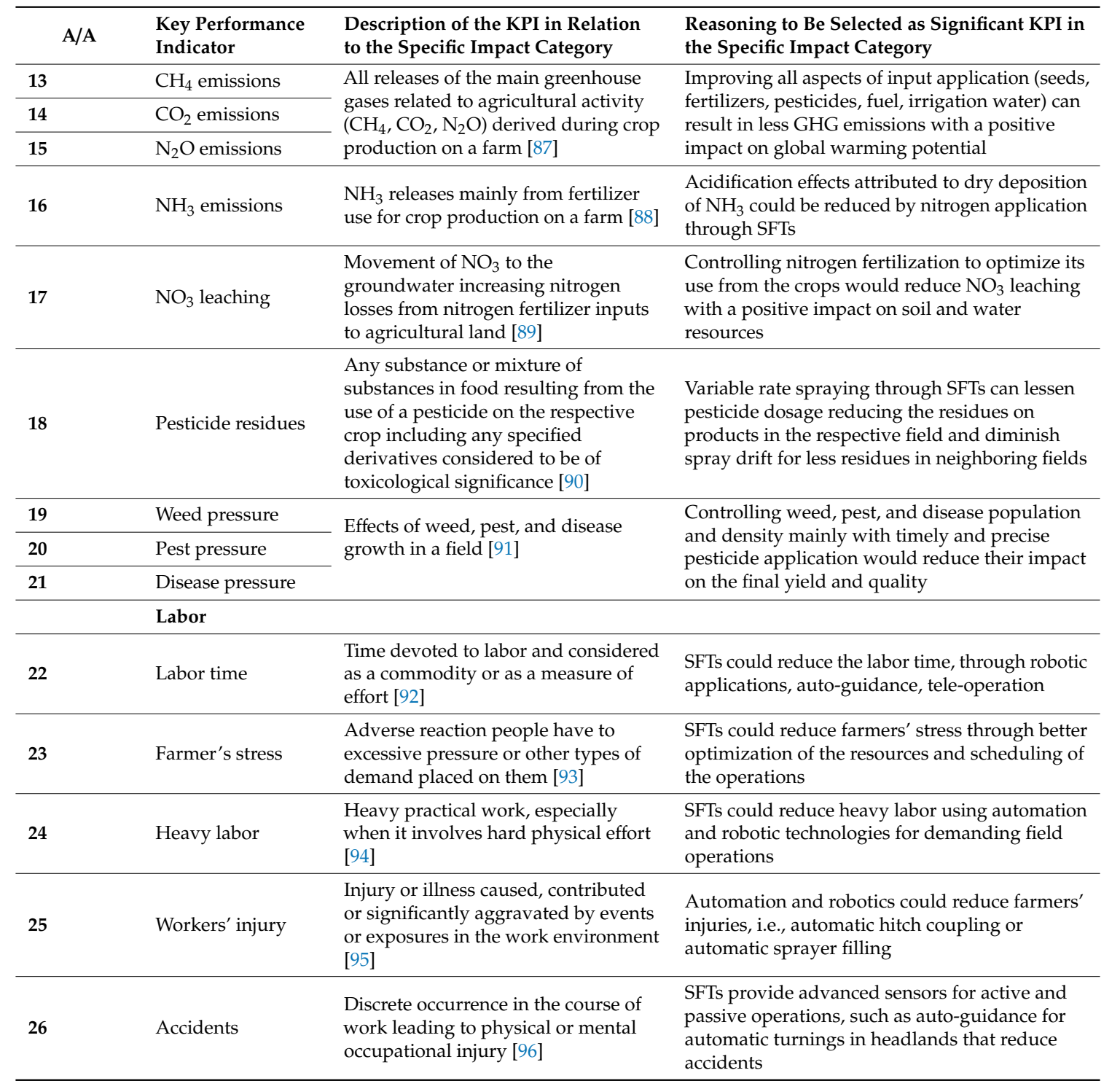

\subsection{Search}

We searched for SFTs derived from scientific papers, research projects, and industrial products. The methodology used is given below.

\subsubsection{Peer-Reviewed Scientific Papers}

We employed Scopus (www.scopus.com) as it has a broad coverage including many disciplines (not just agriculture) and scientific journals of different ranking (not only top journals).

A query was developed in consultation with a professional librarian to search articles that might describe SFTs. The query consisted of two parts: a first part that aimed to select all articles related to technology, and a second part that aimed to select all articles related to open-field farming. The two parts of the query were joined with an "AND" clause. The selection of keywords was supplemented by considerations on the scope of relevant time and subject related settings. The following query was used to select articles:

(TITLE-ABS-KEY (sensor or decision-support or DSS or database or ICT or automat* or autonom* or robot* or GPS or GNSS or "information system" or "image analysis" or "image processing" or "precision agriculture" or "smart farming" or "precision farming")) 
AND

(TITLE-ABS-KEY (agricult* or crop* or arabl* or farm* or vineyard or orchard or horticult* or vegetabl*))

AND (LIMIT-TO (DOCTYPE, "ar") OR LIMIT-TO (DOCTYPE, "re")) AND (LIMIT-TO (SUBJAREA, "AGRI") OR LIMIT-TO (SUBJAREA, "ENGI")),

where keywords ending with "*" could have different endings (e.g., automat* will retrieve "automatic", as well as "automated"); GPS-global positioning system, GNSS—global navigation satellite system.

Results were limited by year, document type (article), subject type (agriculture), and language (English). For our purpose, we collected papers only from 2012 and later, in order to focus on recent SFTs that are likely of interest to all related stakeholders and especially end-users. The query was optimized and verified by using a random sample of 10 key papers that were considered relevant to the development of SFTs practical for farmers. The query was considered completed when these 10 papers were included in the query result.

The Scopus query resulted in a large number of articles that are expected to hold information on SFTs. From these papers, there were many that were not relevant to the open-field agriculture. Therefore, a manual selection procedure was used to select only the articles that are relevant, namely, articles describing a technology that can (or could be) used by a farmer in their daily farming practice. Throughout, we focused on the question, "is this a relevant SFT?". We used an exclusion approach and removed papers related to (i) post-harvest, processing, distributing, or marketing, (ii) evapotranspiration calculations, (iii) land suitability (selecting only DSSs related to crops suitability), (iv) water management, like droughts (but including anything related to irrigation), (v) tractor engines, and (vi) greenhouse cultivation.

Having available only the scientific papers relevant to our search, the manual selection of articles continued in three rounds. Firstly, we used the title to remove papers that were not relevant. For example, a paper with the title "A New Assessment of Soil Loss Due to Wind Erosion in European Agricultural Soils Using a Quantitative Spatially Distributed Modeling Approach" was selected by our query because its abstract contained the terms "geographic information system" and "arable land". However, the title clearly does not describe a tool useful to farmers. Therefore, we removed it from our list. Secondly, for those papers with relevant titles, we also read the abstract and excluded those not practically useful for farmers. As an example, a paper with the title "Wireless Sensor Network and Internet of Things (IoT) Solution in Agriculture" seemed of interest. The abstract made it clear that this paper described network infrastructure that could certainly be used in a farm. However, this would not be used directly by farmers. Rather it would be a component in the development and operationalization of a sensor network that in turn would support tools for decision-making by farmers. In short, this paper did not describe an SFT directly useful for a farmer in open-field agriculture, and it was excluded. As a third step, we attempted to locate the full text of the paper. If that proved impossible, or if the paper turned out to be written in a language other than English, then we removed from the list. If the full text indicated that the paper was not relevant to open-field agriculture, it was also removed from the list. For papers left at the end of step three, the authors answered the questions of the survey of Section 2.3 using the full text of the paper.

\subsubsection{Research Projects}

For the retrieval of research projects, an active search was carried out for EU-funded projects. Horizon 2020 and FP7 programs were collected from the CORDIS [97] website of the EU and imported into a relational database. The Scopus query was translated to an SQL query which searched columns "title" and "objective" for EU research projects, using the same list of keywords as in the Scopus query. In this process, the authors answered the questions of the survey of Section 2.3 using the information of the project's website and deliverables and, in many cases, via personal communication with the projects' coordinators. 


\subsubsection{Industrial Products (Commercially Available Products and Services)}

For the collection of industry results, a call was announced through the Smart-AKIS project newsletter (www.smart-akis.com), as well through the European Association of Agricultural Machinery (CEMA) to become known by the network of SFT companies under its umbrella or related to the association. A web search gave insight into the companies that are possibly involved in the development of SFTs. We searched for companies with relevant credentials for smart farming, such as involvement in the production of farming equipment and machinery or stakeholders involved in the development of agronomic software. The relevant networks of FIWARE FRACTALS and Smart Agrifood II were consulted. Furthermore, we used all Smart-AKIS partners network of advisers to contact relevant stakeholders, and the last step was for the authors of this work to conduct a desk search though internet to locate more commercial SFTs. The questionnaire was answered by the SFT providers with the assistance of the authors of this work. In the case that the questionnaire was inadequately filled in, the SFT providers were contacted again (the questionnaire asked for their consent to do so) to provide the missing or inconsistent information. If the questionnaire was still not totally filled in, then the SFT was excluded from the search.

\subsection{Questionnaire Development}

A questionnaire was constructed for recording data about each SFT found in the three categories (scientific papers, research projects, commercial products). The questionnaire was developed based on the assessment of the full list of challenges and respective KPIs, and three versions were produced (one for each category). The questionnaire consisted of two main parts: (1) descriptive information for the SFT, including basic information, technology readiness level, type, and field operation that it is used for; (2) assessment information about ease of adoption and possible effects on farm economics, environment, and labor. The assessment section was evaluated using a Likert scale of five levels. The responses were analyzed using descriptive statistics for Likert data in R software (free software by the R Foundation from Statistical Computing, Vienna, Austria). The questionnaire was also based on the EIP-AGRI common format [98] as much as possible, and it was distributed online via a link to the identified stakeholders. The specific content of each part in the questionnaire is described below.

\subsubsection{Basic Information about SFT}

After questions that were specific to the type of entry (scientific paper, research project, or industrial product), some basic information questions were asked about the SFT. Indicatively, for papers, the authorship, scientific journal, year of publication, and DOI were asked, while, for projects, duration and status (ongoing or terminated), type of EU funding, budget, and the coordinator were given. Finally, for products, the details of the company and the person in charge were defined.

\subsubsection{Technology Readiness Level (TRL)}

The TRL of a technology indicates its maturity level and ranges from TRL1 (basic principles observed) to TRL9 (actual system proven in operational environment) [99]. Based on this classification, TRL was specified for the SFTs presented in scientific papers and the research projects, while, for commercial products, it was considered as TRL9 because they are already operational on the market. TRL was defined by the authors using the AFRL TRL Calculator (version 2.2.) [100] for each of the included SFTs in the search. The process was as follows: three equal batches of SFTs from both scientific papers (177 papers in each batch) and research projects (two batches of 31 projects and one batch of 32 projects) were respectively defined. Then, each author was assigned with two batches of each category, in order to remain neutral in all papers, and projects of the third batch. In case of disagreement about the TRL level of a certain SFT between the two authors that assessed the same batch, the third author would be asked to evaluate, and his assessment would be taken into account. It should be mentioned that the level of disagreement was very low (in 17 out of 531 scientific papers (3\%) and in six out of 
94 research projects $(6 \%))$, and it remained between two neighboring TRL levels due to the accurate definitions given by References $[77,78]$ and the experience of the authors.

\subsubsection{Typology of SFTs}

For a better understanding of the SFT landscape, the classification of Schwarz and Herold [101] was used. These authors classified SFTs as recording, reacting, or guiding technologies. In addition to these classes, in this work, "FMIS" and "robotic/automation system" were used, because research, innovation, and market application of these SFT categories found high interest in recent years [28,52,59]. It should be noted that these five classes are not mutually exclusive, meaning that a particular SFT may be recording and reacting at the same time. A robotic SFT will typically use some kind of guiding technology and either record or react, or possibly do both. The principal function was used in our analysis.

\subsubsection{Field Operation Conducted with the SFT}

The main field operations that each SFT could be used were given in the questionnaire to be chosen, namely, (1) tillage, (2) sowing, (3) transplanting, (4) fertilization, (5) pesticide application for weed, pest, and disease control, (6) irrigation, and (7) crop scouting (measuring and recording crop and soil parameters in the field), for example, in the situation of field data retrieval. The option to include another field operation was provided.

\subsubsection{Ease of Adoption of the SFT}

In addition to characteristics of SFTs that relate to the challenges that farmers face, there were also questions related to ease of adoption of SFTs. The Rogers method [102] for evaluation of innovations was used, where potential adopters evaluate an innovation in terms of its relative advantage (the perceived efficiencies gained relative to current tools or procedures), compatibility with the pre-existing system, complexity or difficulty to learn, testability, potential for reinvention (using the tool for initially unintended purposes), and observed effects. Respondents were asked to indicate whether or not they agreed with the following seven statements, using the Likert scale in five levels of agreement (strongly disagree, disagree, no opinion, agree, and strongly agree):

1. The SFT replaces a tool or technology that is currently used. The SFT is better than the current tool.

This question is specifically targeted at SFTs that aim at creating added value over existing tools.

2. The SFT can be used without making major changes to the existing system.

Some SFTs are expected to require more changes to the existing system than others.

3. The SFT does not require significant learning before the farmer can use it.

This statement can give an indication on the learning effort that needs to be made by the farmer and can be useful in order to compare the difference in learning requirements between SFTs.

4. The SFT can be used in other useful ways than intended by the inventor.

Some SFTs may hold multiple purposes useful for the achievement of many very different effects.

5. The SFT has effects that can be directly observed by the farmer.

It is considered an advantage when effects can be directly observable by a farmer, as it will make it more likely that the farmer will find the SFT relevant for their situation.

6. Using the SFT requires a large time investment by the farmer. 
This statement will give an indication on the time investment that is needed from the farmer in order to use the SFT, which will play a role in how attractive the SFT is to use.

7. The SFT produces information that can be interpreted directly (example of the opposite: the SFT produces a vegetation index but nobody knows what to do with it).

It is desirable when results are presented in such a manner that they are easy to interpret. This makes the results more interesting for end-users and results in interpretation consistency.

\subsubsection{Effect of Using the SFT}

A very important part of this work was to define the effect of each SFT in agricultural production. The identified KPIs in Section 2.1 were used as criteria to measure the impact on farm economics, the environment, and labor within the farm. Effects were expected on these 26 critical aspects, of which five are influenced positively by the SFTs, increasing them (productivity; quality of a product; revenue; soil biodiversity; biodiversity), and 21 are affected positively by the SFTs, decreasing them (input costs; variable costs; crop wastage; energy use; $\mathrm{CH}_{4}$ emissions; $\mathrm{CO}_{2}$ emissions; $\mathrm{N}_{2} \mathrm{O}$ emissions; $\mathrm{NH}_{3}$ emissions; $\mathrm{NO}_{3}$, emissions; fertilizer use; pesticide use; irrigation water; labor time; farmers' stress; heavy labor; injury; accidents; pesticide residue; weed pressure; pest pressure (insects); disease pressure). Effects could be expressed using the Likert scale in five levels of change (large decrease, some decrease, no effect, some increase, and large increase). The respondent could supplement this scale with relevant percentages or even more precise indication of the effects of the SFT when this was possible.

\section{Results and Discussion}

This section provides the final number of SFTs identified in scientific papers, research projects, and commercial products through our search. These SFTs were presented and compared in terms of technology readiness level (TRL1-9), type (recording, reacting, guiding, FMIS, and robotic/automation), and field operations addressed (tillage, sowing, transplanting, fertilizing, weeding, crop protection, irrigation, harvesting, scouting). This was used to present some perspective trends of the current situation in SFT development. The factors that were expected to affect adoption readiness of SFTs were also described, while the effect on farm economics, the environment, and labor was given, in order to identify the most impactful categories of SFTs within the inventory of this work.

\subsection{Numbers and Kinds of SFTs}

The number of articles describing an SFT is growing rapidly (Figure 1), showing the trend of research to transfer conventional agriculture based on the Green Revolution concept (agricultural mechanization, uniform input application) to a modern smart agriculture (ICT interference in agricultural machinery for increased precision and specified input application).

In total, 13,251 scientific papers were found in the citation database Scopus with the query described in Section 2.2, and the manual selection resulted in a small fraction of these scientific papers (531 or $4 \%$ of the total) being selected based on the deployment of a prototype tested in field conditions, which can be directly useful to farmers. This low percentage of the total number of scientific papers indicates that most research presented mainly immature concepts that require several steps before they can be beneficial for everyday agricultural practices. 


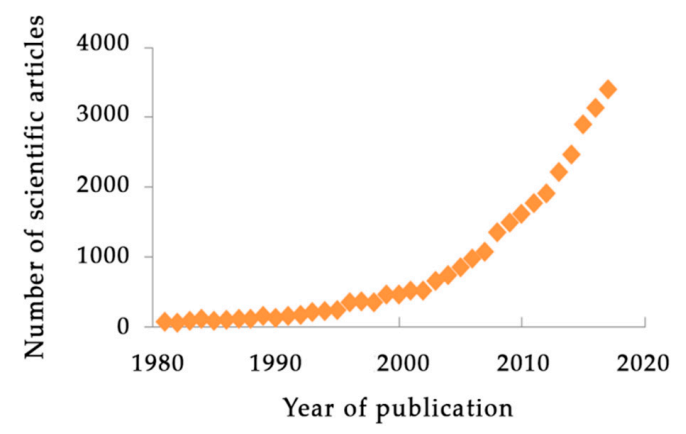

Figure 1. Temporal evolution of published scientific articles on smart farming technologies (SFTs) on a yearly basis (for the period 1981-2017) identified through a Scopus query (as of 18 July 2018). The query selected articles that contained keywords related to technology (sensor, decision support, DSS, database, ICT, automat*, autonom*, robot*, GPS, GNSS, information system, image analysis, image processing, precision agriculture, smart farming, precision farming) and to open-field farming (agricult*, crop $^{*}, \operatorname{arabl}^{*}$, farm* ${ }^{*}$, vineyard, orchard, horticult*, vegetabl* ${ }^{*}$. ICT-information and communication technologies; GPS—global positioning system; GNSS—global navigation satellite system.

The European Commission CORDIS online database with a search for funded projects resulted in 94 research projects from FP7 and H2020 funding frameworks directly related to SFTs, while the search for industrial SFT solutions concluded 439 products that are available on the market for farmers to purchase. In total, 1064 SFTs were selected for this analysis for all categories (Table 3), for which the questionnaire was completed.

Table 3. Total number of smart farming technologies (SFTs) identified by the search conducted in available scientific papers, research projects and industrial products.

\begin{tabular}{cc}
\hline Type & Total Number \\
\hline Research articles & 531 \\
Research projects & 94 \\
Industry solutions & 439 \\
Total & $\mathbf{1 0 6 4}$ \\
\hline
\end{tabular}

\subsection{Technology Readiness Level (TRL) of SFTs}

Figure 2 presents the differences in TRL between the scientific papers and research projects (by definition, the TRL of commercial products is 9).

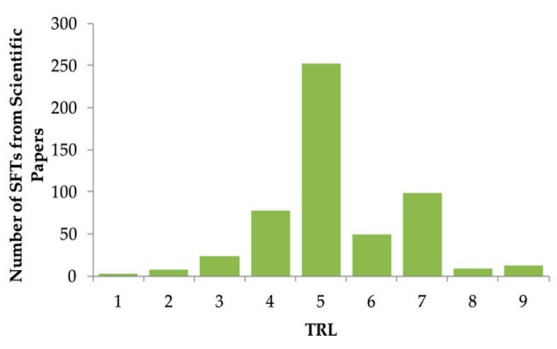

(a) Scientific Papers

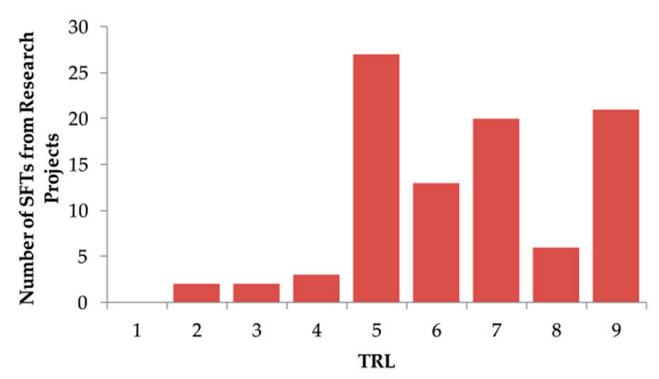

(b) Research Projects

Figure 2. Technological readiness level (TRL) of the identified smart farming technologies (SFTs) in (a) scientific papers and (b) research projects. TRL ranges from TRL1 (basic principles observed) to TRL9 (actual system in operational environment) [99] and was defined using the AFRL TRL Calculator (version 2.2.) [100]. Commercial SFTs were excluded by this process (they all had TRL9). 
Most technologies were at the stage where they are validated in a relevant environment. In all cases, a few entries were of the earliest stages in which only basic principles were observed or technology concepts formulated. In research projects, it can be seen that the majority had TRL5-7, but an important finding is that $16 \%$ of projects resulted in a commercial product (TRL9), showing the recent trend of projects focusing on an alliance between academia and businesses for real applications.

\subsection{Types of SFTs}

Different types of SFTs can be distinguished in scientific papers, research projects, and commercial products (Figure 3). By focusing on just scientific papers published across the six years under consideration, it is obvious that there was a focus on recording, with relatively little attention toward reacting. This is not a comforting picture, because it suggests that, while there is a large effort on measurements, there is a lack of effort on translating measurements into on-farm practical actions. It should be noted that this outcome corresponds uncomfortably well with the general belief that SFTs promise more than they deliver (e.g., see Reference [103]). However, this finding was not shown in research projects and commercial products to such an extent.

\begin{tabular}{|c|c|c|c|c|c|c|}
\hline & \multicolumn{2}{|c|}{ (a) Scientific Papers } & \multicolumn{2}{|c|}{ (b) Research Projects } & (c) Commercic & oducts \\
\hline & No. of SFTs & $\%$ & No. of SFTs & $\%$ & No. of SFTs & $\%$ \\
\hline Recording & 286 & 53.9 & 25 & 26.6 & 128 & 29.1 \\
\hline Reacting & 78 & 14.7 & 8 & 8.5 & 68 & 15.5 \\
\hline Guiding & 23 & 4.3 & 3 & 3.2 & 30 & 6.8 \\
\hline FMIS & 87 & 16.4 & 41 & 43.6 & 137 & 31.2 \\
\hline Robot/Automation & 57 & 10.7 & 17 & 18.1 & 76 & 17.3 \\
\hline Total No. of SFTs & 531 & 100 & 94 & 100 & 439 & 100 \\
\hline
\end{tabular}

Figure 3. Allocation of the identified smart farming technologies (SFTs) to each type (recording, reacting, guiding, farm management information systems (FMIS), and robotic/automation systems) based on the classification of Schwarz and Herold [101] modified by the authors in (a) scientific papers, (b) research projects, and (c) commercial products.

Regarding the research projects, it can be seen that the EU funding was directed more toward FMIS development followed by recording technologies. This might have happened as measured in-field data have to be translated into information through ICT tools for supporting farms' statistics and farmers' decisions [33], which is the first step before reacting. Reacting SFTs were also supported by the EU, but to a lower extent, suggesting that this SFT type is also under development. An important reading of Figure $3 \mathrm{~b}$ is also that robots and automation for agricultural use received attention and were funded even more than other reacting SFTs. This may be explained by such SFTs being perceived as a solution in applying smart farming applications in field conditions using their advantages (small size, in-field precise navigation) [104]. This trend could also be associated with the specificity of field plots in Europe being much smaller compared to the US [105], making a small robot or swarms of small robots much more of interest for European agriculture [58].

As for the industrial products (Figure 3c), there was a more uniform distribution between SFT categories. Only guidance technologies were found less often in our search, probably because they 
are the most mature commercial SFTs [106] and limited new companies are entering the market. It is important to point out that recording technologies and FMIS have the largest number of SFTs, partially following the trends in both scientific papers and research projects. Reacting and robotic/automation technologies were also significantly represented in the commercial product inventory, even if research (papers and projects) did not seem to focus on these subjects to a high extent (Figure 3). Regarding robotic/automation SFTs, the number of available market solutions seemed disproportionately high in comparison to research outcomes in the same field. In our findings, there was an increasing trend for these technologies moving from scientific papers to commercial products. This may be because agricultural research experienced a delay in coping with the development of these high-end SFTs, and companies using internal research and development produced marketable products without publishing this work in scientific journals for intellectual property reasons. These companies either collaborate in large consortiums of EU research projects to optimize and market such products or go directly by their own means in marketable products. In addition, higher funding for infrastructure in research groups is required to carry out work with robotic systems, and this may have also influenced the low number of robotic/automation SFTs in research projects and scientific papers in comparison to other SFTs, such as recording technologies.

\subsection{Field Operations Addressed by the Identified SFTs}

The field operations that the identified SFTs were used for are summarized in Figure 4.

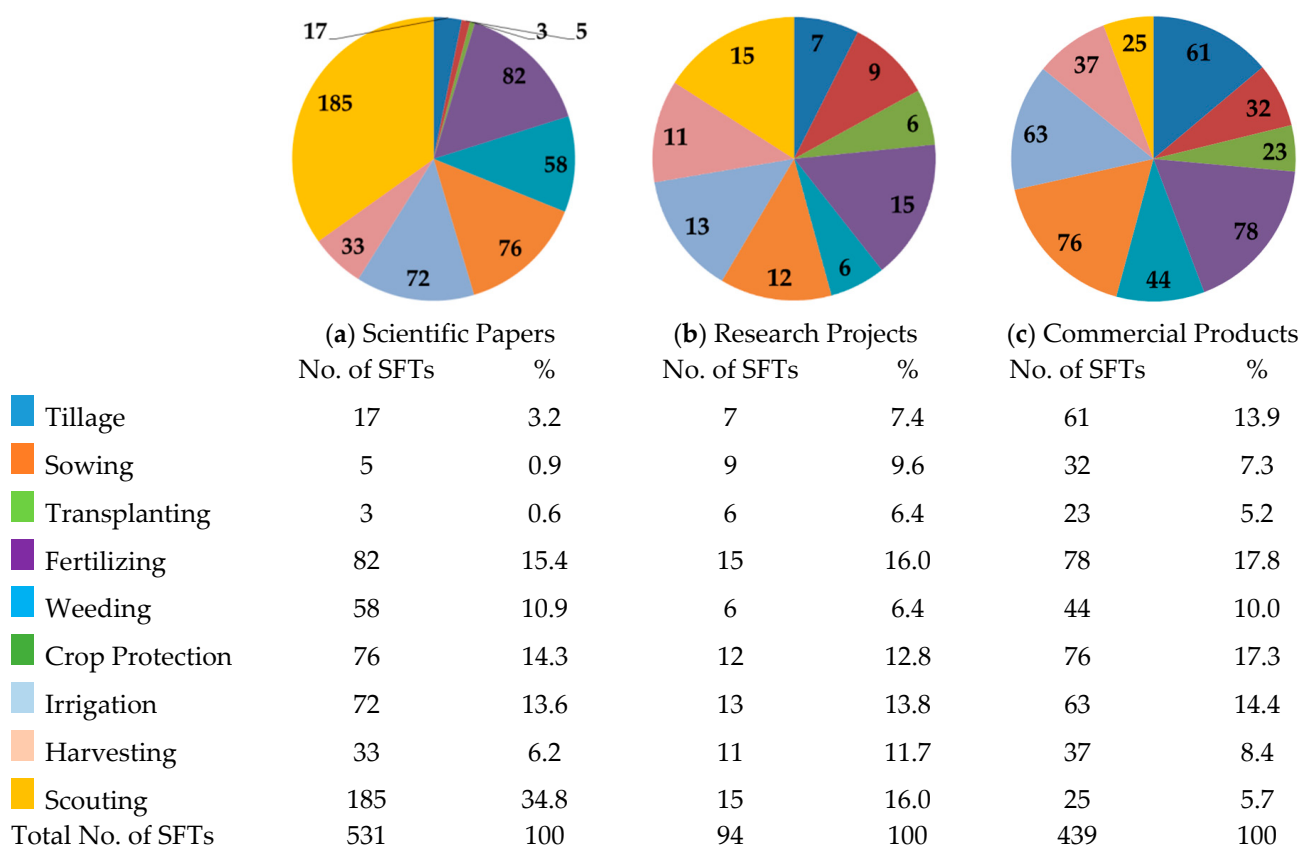

Figure 4. Allocation of the identified smart farming technologies (SFTs) to each category that addresses a certain field operation (tillage, sowing, transplanting, fertilizing, weeding, crop protection, irrigation, harvesting, and crop/soil scouting) in (a) scientific papers, (b) research projects, and (c) commercial products.

In scientific papers, crop and soil scouting was the most common application for the SFTs described, in accordance with the trend of Figure 3, where recording SFTs were the most prominent. On the contrary, SFTs derived from scientific papers focused very little on soil tillage and sowing/transplanting, even though they can provide significant savings in plant establishment and increase yield potential (especially in hybrid seeds, such as corn and potatoes). On the other hand, this work confirms that reacting application technologies are of great importance for researchers (also due to farmers' interests in these subjects), as also seen in the literature with fertilizing $[107,108]$, weeding [109], 
crop protection [110], irrigation [111], and harvesting [61,112] being important research subjects in recent years.

The best represented subjects in research projects were fertilization and crop/soil scouting. Fertilization is indeed one of the targets for variable rate application to ensure yield maintenance or even increase yield with the least possible nutrients applied [107], and EU research projects seem to fund this issue to a great extent. As for scouting, it is often chosen simultaneously with other field operations (most often together with fertilization) and, in only $22 \%$ of cases, it is the only chosen field operation. This result presents the need for data gathering before any smart field application, as stated in many SFT-related publications [113-115]. Tillage, sowing/transplanting, and weeding were less found, as in the scientific papers. Research on these operations is indeed lacking, and the reason may be the reluctance of researchers and funders to carry out research in this domain, probably due to the fact that it is still unclear how effective it is and how it fits with other variable rate technologies. However, the most crucial conclusion from Figure $4 \mathrm{~b}$ is that EU-funded research is well distributed among research topics and is generally directed to all agricultural practices.

Regarding the industrial products, the situation is different as scouting had a significant number of SFTs identified, but not the majority, as seen in scientific papers and research projects. This might indicate that industrial solutions are slowly moving to integrated systems (required equipment for data acquisition and actuation combined). On the other hand, fertilization remains the most important SFT sold on the market as in papers and projects, followed by crop protection and irrigation, which are the three most crucial agricultural practices for most crops. Since the SFT market in the EU is still in its infancy, companies are directed mainly toward these applications that are of high importance for farmers. Companies that will survive or even evolve rapidly need to demonstrate dynamic capabilities (in this case, to offer effective and efficient SFTs with tangible results), move beyond conventional agricultural machinery and gain a competitive advantage that generates long-term Schumpeterian rents [116]. It is interesting to point out that not only tillage, but also sowing/transplanting have significant representation in the industrial SFTs, possibly illustrating that such technologies are already mature in the market (or at least their accuracy is adequate for practitioners) and, therefore, research was not directed toward them in recent years.

\subsection{Factors That Can Be Expected to Affect Adoption of SFTs}

Based on the seven statements of the Rogers framework (Section 2.3.5), the inventoried SFTs were assessed in terms of affecting adoption readiness. The results for scientific papers, research projects, and industrial products are shown in Figure 5.

By comparing the results of the three SFT categories, it is obvious that there is a constant trend of change for all seven statements of the Rogers framework, moving from scientific papers (new ideas with low TRL) to research projects (more mature ideas with higher TRL) and finally industrial products (mature commercial solutions of TRL9). More specifically, SFTs presented in scientific papers are not indicated as a significant replacement of an existing tool, while this is quite more prominent for most of the SFTs listed in research projects and commercial products. Probably, new SFTs developed from scientists are yet to find their actual place in agricultural practice, while, in projects and especially in H2020 EU projects, the role of and the need for the developed SFTs were already identified from scratch. As for the commercial SFTs, one of the main reasons for a product to be marketed is its ability to replace existing technology and to ease the end-user's business $[117,118]$.

Regarding the need for major changes in existing systems, researchers in scientific papers are working on radical concepts that will make a change in existing farming practices, while research projects and, to a greater extent, commercial products are directed toward solutions that can cover the needs of farmers by adjusting their existing systems [29]. SFTs in scientific papers seem to require less learning from the end-user than those in research projects and commercial products. This result was expected, as researchers believe that their ideas are easily interpreted by a user as they have great knowledge of what they are working on, while, as the SFT moves into real conditions, it becomes 
obvious that a typical farmer will have to be taught these new ICT solutions that they are not used to by increasing their SFT literacy, which is one of the main barriers for SFT adoption [119].

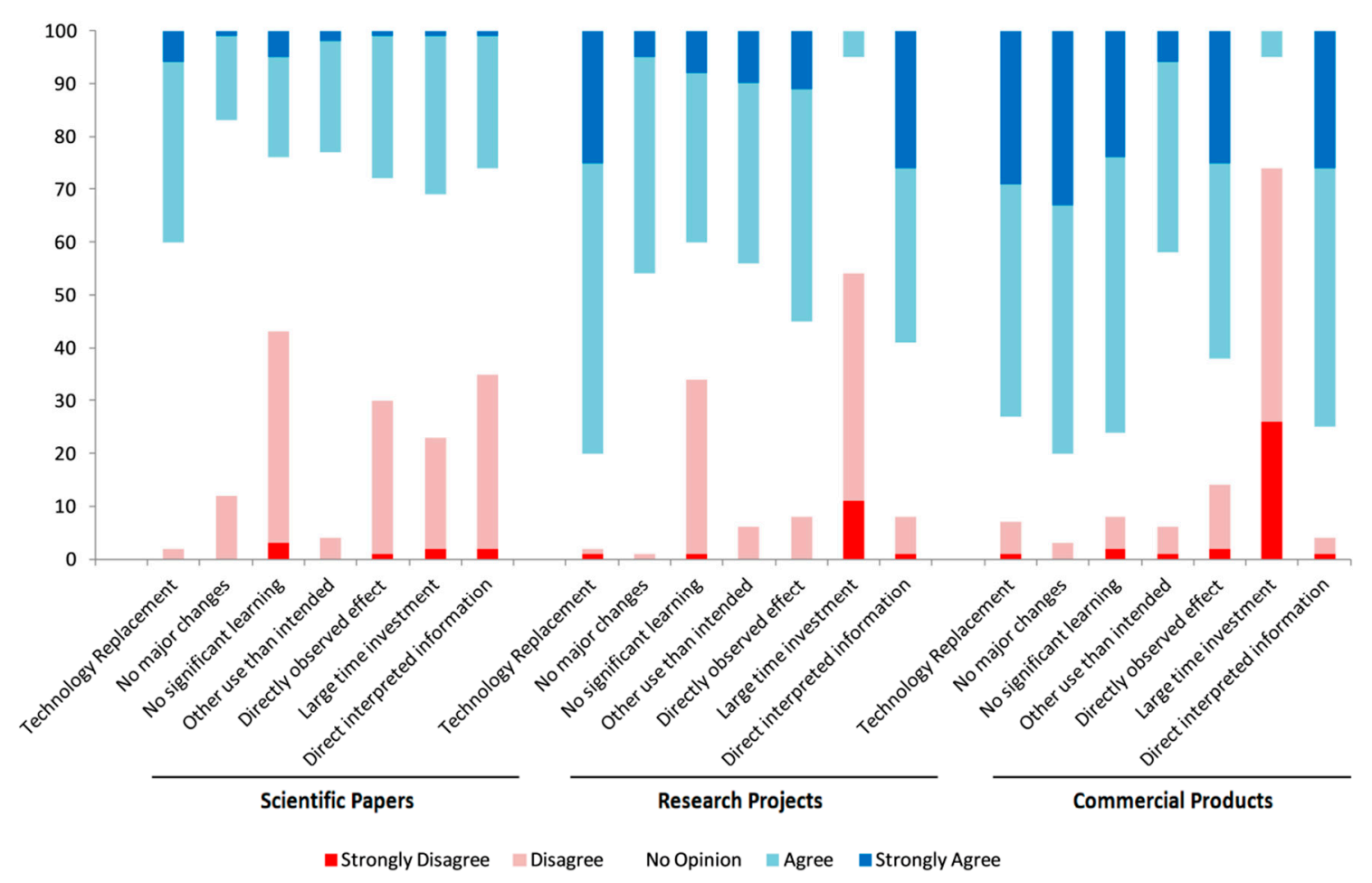

Figure 5. Responses regarding adoption readiness of the smart farming technologies (SFTs) identified in scientific papers, research projects, and commercial products using the Rogers framework [102] based on a Likert scale of five levels (strongly disagree to strongly agree).

A typical invention presented in a scientific paper cannot be thought of as a solution for other purposes than the one it was directed to and, hence, it was not indicated as such. SFTs in research projects and in commercial products are more able to be used for other purposes than intended due to their closer relationship with everyday farming and their higher compatibility with existing machinery, which nevertheless remains a significant barrier, even in industrial SFTs $[29,63,120]$. The direct effect of SFTs is not visible in immature technologies presented in scientific papers. However, in large research projects and commercial products, these direct effects were investigated more rigorously; for the latter, the need for this investigation stems from a need to be marketed with tangible effects on the farm, i.e., the potential end-user [121,122], which unfortunately remains one of the significant barriers for SFT adoption [64]. Indeed, a major factor in the diffusion of any technology is the acquisition of information by the end-user $[123,124]$. This type of information needs to include, but not be limited to, the benefits of adopting the technology, the compatibility with existing technologies, and relative advantages in comparison with substitute technologies. Naturally, this type of information cannot be conveyed to the end-user when SFTs are still in the early stages of research as presented in scientific papers. While more information can be available to the farmer in large-scale projects, complete information can be more efficiently conveyed in terms of its tangible effects via commercial products.

The time that an SFT requires for its user to be acquainted with was declared as longer in prototypes produced in scientific papers than in research projects and industrial products, where structured manuals and helpdesk support is available from scratch. Finally, an SFT in scientific papers is in most cases immature, and the data derived from it require long processing to provide useful information, while research projects are more mature and industrial products in particular need to make the client's life easier by providing fast and clear information of decision-making. 


\subsection{Effects on Farm Economics, the Environment, and Labor}

The effects on the 26 different aspects described in Section 2.3.6 were different for SFTs derived from scientific papers, research projects, and industrial products (Figure 6). It can be seen that SFTs from scientific papers (Figure 6a) did not focus on their impact, rather than their functionality and reliable results in the promised action [37], while, in research projects (Figure 6b) which mainly involve innovation or research and innovation actions (IA or RIA) [125], the majority of SFT solutions were assessed in terms of economic, environmental, and labor impact, and their benefits were revealed. As for commercial products, Figure $6 \mathrm{c}$ presents that most of the 26 aspects were influenced to an extent between scientific papers and research projects. This fact shows that the rebound effect of using commercial SFTs in everyday farming could reduce the declared positive effects of SFTs in all aspects $[64,65]$. It also indicates that product providers might be modest in what they promise, so that enough positive impacts are provided to the customers to see tangible results and to increase trust in these products. In addition, commercial products were the only category among papers, projects, and products where opposite opinions about their effect were found, which indicates that marketed SFTs which are applied in real conditions are also followed by disadvantages. However, it should be pointed out that, even in this case, the declared negative effects were very limited, showing the potential of SFTs for agricultural production improvement.

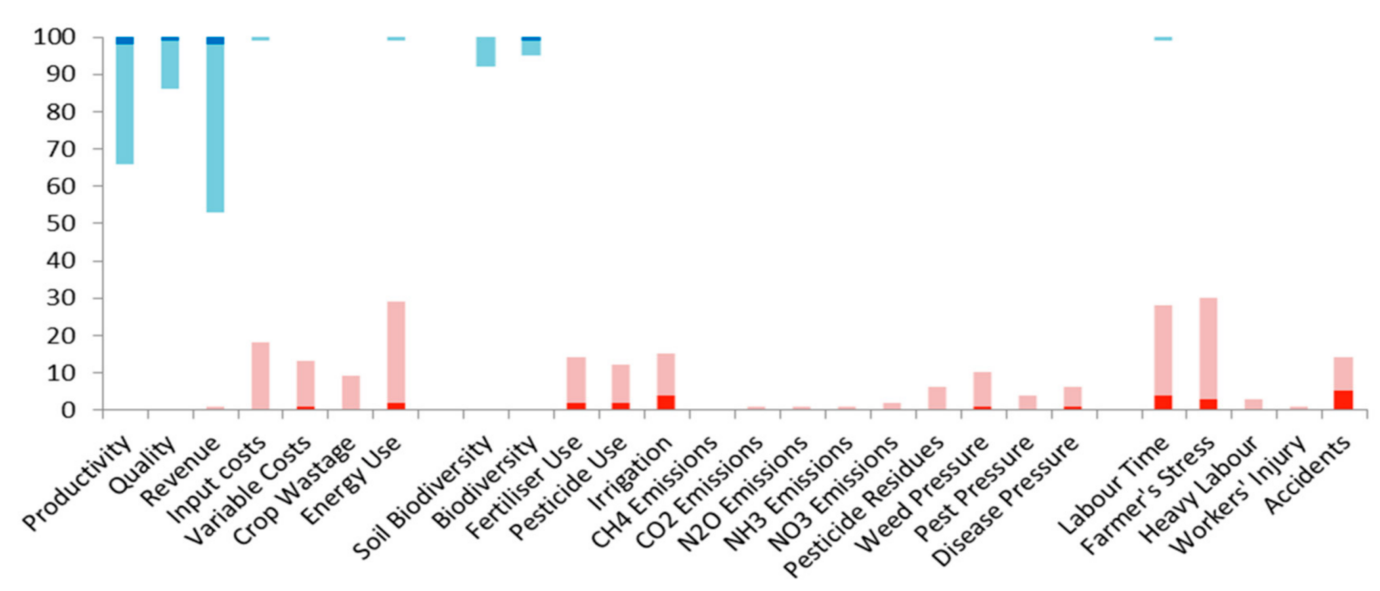

(a)

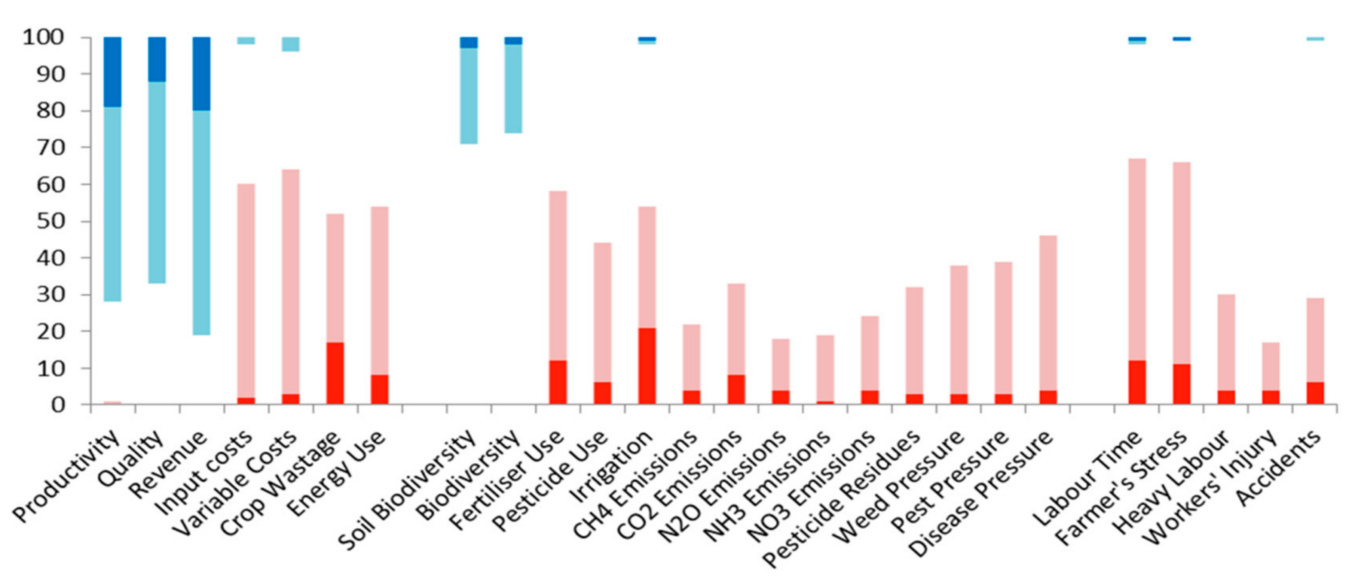

(b)

Figure 6. Cont. 


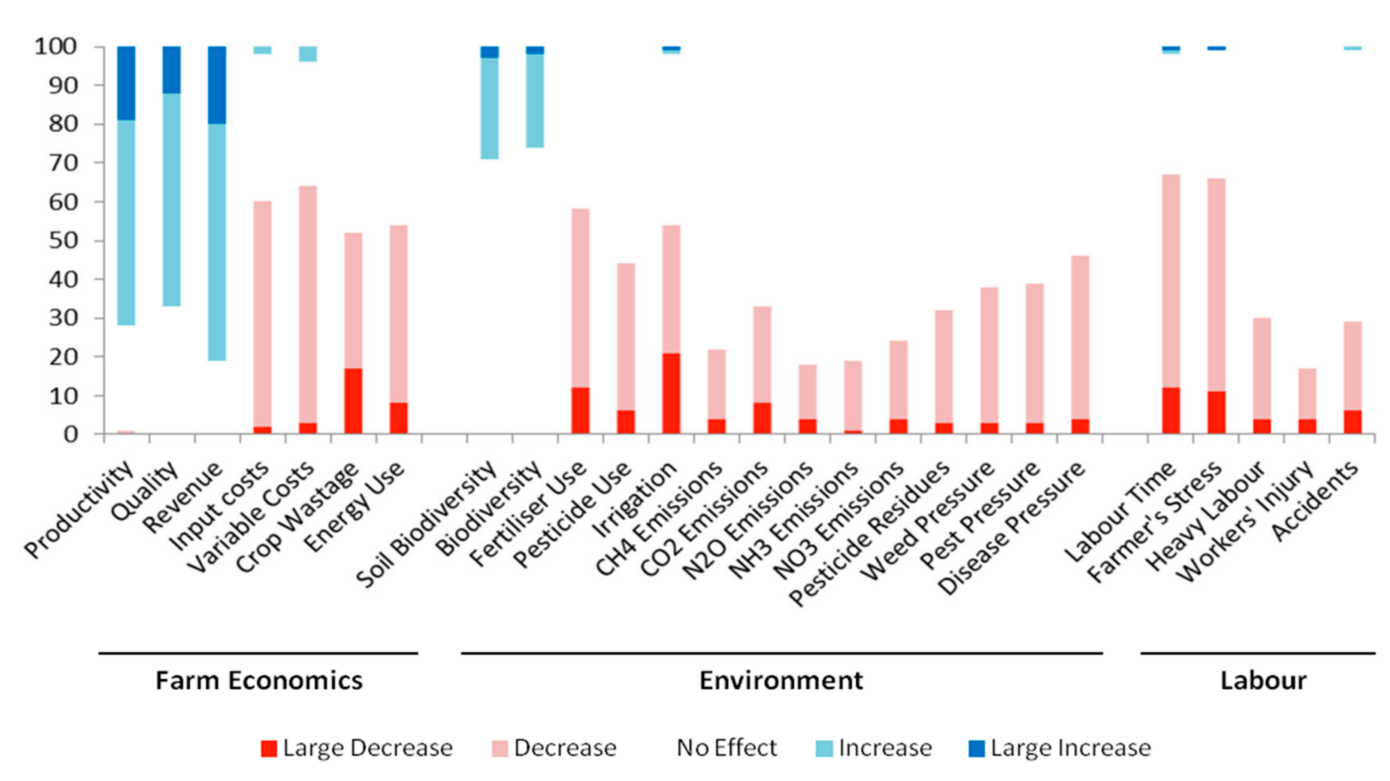

(c)

Figure 6. Effects of the identified smart farming technologies (SFTs) on farm economics, the environment, and labor using a qualitative assessment of SFTs in (a) scientific articles, (b) research papers, and (c) commercial products based on a Likert scale of five levels (large decrease to large increase).

\subsubsection{Farm Economics}

Productivity, revenue, and quality are expected to increase when using all SFTs. Indeed, numerous reviews indicated that SFTs can produce positive economic results in comparison to conventional practices [37,126-129]. These three aspects follow a similar trend of expected increase from scientific papers to research projects and then to commercial products, indicating that innovative SFTs become commercial when it is believed that the economic gains for farms are significant and that this is the main aim of product providers [117]. On the other hand, the remaining economic aspects (input and variable costs, crop wastage, and energy use) followed another trend, with research projects promising higher impacts than industrial products and scientific papers (in this order). This may be explained by research projects assessing several aspects of SFT performance, while scientific papers focus mainly on technological achievements and commercial products in terms of the SFT economic gains for the end-user. Another reason could also be the self-promotion of research projects to cover the expectations of funding authorities.

\subsubsection{Environment}

Among the 14 environmental aspects, the most influenced in all categories were agricultural inputs (fertilizers, pesticides, and irrigation water). This finding is connected with the input and variable cost effect of Section 3.6.1 and with the main principle of SFTs to maintain or increase production with lower agricultural inputs [130]. On the contrary, the least affected aspects were gaseous emissions of all types (with $\mathrm{CO}_{2}$ being the most affected), indicating that either there is limited effect or that it is yet to be investigated thoroughly by researchers and industry [37]. Weed, pest, and disease pressure can also be reduced by SFT application, which is connected to reduced pesticide use that is less needed due to lower pressure. An increase in (soil) biodiversity was also declared, probably because rational input use derived from SFT application reduces the effect on fauna and flora, leading to biodiversity preservation [131]. All environmental aspects were found to be more affected by project SFTs than by product or paper SFTs, showing the same trend as the economic aspects in Section 3.6.1. 


\subsubsection{Labor}

Labor time and farmers' stress were the most affected aspects as SFTs facilitate all agricultural practices. It should be pointed out that, even if farmers' stress is shown to be reduced significantly, the actual use of an SFT can involve quite some upfront stress, because of the need to process information and calibrate the technology, as well as when technologies fail. Stress level is different among SFT types, with guidance technologies that are functional and efficient for years reducing stress a lot more than variable rate technologies that require detailed and continuous calibration to operate properly compared to conventional uniform application. End-user labor heaviness was also declared to be reduced, while injuries and accidents were not presented as very affected. These findings show how ICT solutions provided by SFTs are supposed to make farmers' lives easier and that they are in line with several research studies on this subject. Meyer-Aurich et al. (2008) [132] showed that precision agriculture technologies can reduce labor due to the automation of variable rate application, while Pedersen et al. (2006) [133] presented that precision agriculture is less labor-intensive and can reduce restrictions on available daily working hours. In addition, Batte (2003) [134] introduced the indirect impact of guidance technologies on the availability of labor for other agricultural work.

\section{Conclusions}

A large number of SFTs (1064) derived from scientific papers (531), research projects (94), and commercial products (439) were collected and analyzed in this work. They were accompanied by additional information about their type and field operation used for, as well as in relation to their adoption readiness expectations and their economic, environmental, and labor impact. Scientific papers mainly focused on recording technologies, while research projects focused on high-end FMIS translating the collected data to valuable decisions. Commercial products were more balanced between SFT types, with recording and FMIS again receiving the highest attention, with reacting and robotic/automation technologies also highly represented, as farmers require executable solutions for their everyday operations. The collected SFTs of scientific papers were mainly used for crop and soil scouting, and the research projects were mostly related to fertilization, while commercial SFTs were directed toward the three most crucial agricultural practices for most crops, namely, fertilization, crop protection, and irrigation.

The factors affecting adoption readiness of SFTs showed a constant trend of change. SFTs from research projects and commercial products were indicated as a significant replacement of existing solutions, but not bringing major changes in existing agricultural systems. SFTs in scientific papers were indicated as requiring less learning from the end-users than in research projects and even more so in commercial products. Finally, data from SFTs in scientific papers were difficult to interpret into useful information, while research projects and especially industrial products provided clearer information to the end-user.

The economic, environmental, and labor effects of the inventoried SFTs were different in scientific papers, research projects, and industrial products. Scientific papers did not provide specific impact statements, while benefits or drawbacks of SFTs in research projects were highly investigated, as this is required by research funding agencies; commercial SFTs were also declared to have adequately high impact. Regarding farm economics, commercial SFTs were indicated as having the highest expected increase in productivity, revenue, and quality, while, for input and variable costs, crop wastage, and energy use, SFTs from research projects promised higher impacts than commercial products and scientific papers. As for the environmental impact, the most influenced environmental aspects in all categories were agricultural input reduction (fertilizers, pesticides, and irrigation water). On the contrary, the least affected aspects were gaseous emissions of all types. In terms of labor, working time and farmers' stress were the most affected aspects, while work heaviness was also declared to be reduced; injuries/accidents were not affected to a high extent.

From this work, it was revealed that research is slowly shifting from recording technologies to actuation technologies, while the share of scientific papers on reacting and robotics/automations is 
increasing (albeit from a low base). However, recording technologies still occupy the majority of SFTs with many new (types of) sensors and measurement methods found, especially in scientific papers.

This seems to indicate that there is a knowledge gap between, on the one hand, measuring the status of crop and soil and, on the other hand, using that information to make practical decisions in farming. Therefore, research is needed to provide the knowledge that will allow recording SFTs to be applied in practice. In particular, more research is needed to provide optimized algorithms, easily calibrated sensor/application equipment, and higher application precision for variable rate pesticide or fertilizer application, as well as variable rate seeding and tillage. It is expected that robots/automation for weed control and other operations will deliver large benefits in reducing labor demand and input use; however, at present, few SFTs can be classified as such. Therefore, research should also be directed toward these technologies, a trend that was also shown by our work.

Finally, only a few SFTs identified in our inventory explicitly addressed issues related to data management, such as ownership, data transfer, sharing, security, and privacy. This is not surprising because these issues are, to a large degree, organizational issues that cannot be solved by a technology alone. It is clear that technical, social, and legal barriers related to collecting, storing, and transferring data hinder farmers' transition to smart farming, and data security and privacy implications resulting from a security breach are a major concern for the digitization process of agriculture.

It was concluded that the inventory of SFTs described in this study is important in the sense that it provides researchers with existing SFT developments to seek new research challenges, policy-makers with information on the current status of SFTs to design incentives for higher adoption rates, and farmers with an opportunity to acquaint themselves with the SFTs that are available. However, this work also identified the fact that researchers and SFT providers in most cases did not produce quantitative impact results with the use of their SFTs, which makes our study still indicative about the impact of SFTs, as we analyzed mainly qualitative criteria. In addition, this inventory should be updated regularly as the technology is moving fast and new farmers are getting more aware of the available SFTs on the market. Therefore, a follow-up to the present study would be beneficial in creating an inventory also including data-related technologies, practices, standards, and agreements, as well as numerical results of SFT impact in real conditions.

Author Contributions: Conceptualization, F.K.V.E., S.F., and A.T.B.; methodology, F.K.V.E., A.T.B., and S.F.; questionnaire filling and survey, A.T.B., F.K.V.E., and S.F.; data analysis, F.K.V.E. and A.T.B.; writing-review and editing, A.T.B., F.K.V.E., and S.F. All authors have read and agreed to the published version of the manuscript.

Funding: This paper was supported by the European Union's Horizon 2020 coordination and support program under grant agreement No. 696264, project Smart-AKIS “European Agricultural Knowledge and Innovation Systems (AKIS) toward innovation-driven research in Smart Farming Technology".

Acknowledgments: The authors would like to acknowledge the contribution of Fenny van Egmond, Michael Koutsiaras, Vassilis Psiroukis, and Dinos Grivakis in the inventory preparation.

Conflicts of Interest: The authors declare no conflicts of interest. The funders had no role in the design of the study; in the collection, analyses, or interpretation of data; in the writing of the manuscript, or in the decision to publish the results.

\section{Abbreviations}

FMIS

DSS

QR

RFID

VRA

RTI

SFMT

SFT
Farm management information system

Decision support system

Quick Response

Radio frequency identification

Variable rate application

Returnable transport items

Smart farming moving technologies

Smart farming technology 


\section{References}

1. Gomiero, T.; Pimentel, D.; Paoletti, M.G. Is There a Need for a More Sustainable Agriculture? Crit. Rev. Plant Sci. 2011, 30, 6-23. [CrossRef]

2. World, B. ICT in Agriculture (Updated Edition): Connecting Smallholders to Knowledge, Networks, and Institutions; World Bank: Washington, DC, USA, 2017.

3. Wang, N.; Zhang, N.; Wang, M. Wireless sensors in agriculture and food industry-Recent development and future perspective. Comput. Electron. Agric. 2006, 50, 1-14. [CrossRef]

4. Aqeel ur, R.; Abbasi, A.Z.; Islam, N.; Shaikh, Z.A. A review of wireless sensors and networks' applications in agriculture. Comput. Stand. Interfaces 2014, 36, 263-270. [CrossRef]

5. King, A. Technology: The Future of Agriculture. Nature 2017, 544, S21-S23. [CrossRef]

6. Toth, C.; Jóźków, G. Remote sensing platforms and sensors: A survey. Isprs J. Photogramm. Remote Sens. 2016, 115, 22-36. [CrossRef]

7. Mahan, J.R.; Yeater, K.M. Agricultural applications of a low-cost infrared thermometer. Comput. Electron. Agric. 2008, 64, 262-267. [CrossRef]

8. Polo, J.; Hornero, G.; Duijneveld, C.; García, A.; Casas, O. Design of a low-cost Wireless Sensor Network with UAV mobile node for agricultural applications. Comput. Electron. Agric. 2015, 119, 19-32. [CrossRef]

9. Kumar, A.; Kamal, K.; Arshad, M.O.; Mathavan, S.; Vadamala, T. Smart irrigation using low-cost moisture sensors and $\mathrm{XBee}$-based communication. In Proceedings of the IEEE Global Humanitarian Technology Conference (GHTC 2014), San Jose, CA, USA, 10-13 October 2014; pp. 333-337.

10. Kumar, S.A.; Ilango, P. The Impact of Wireless Sensor Network in the Field of Precision Agriculture: A Review. Wirel. Pers. Commun. 2018, 98, 685-698. [CrossRef]

11. Rose, D.C.; Chilvers, J. Agriculture 4.0: Broadening Responsible Innovation in an Era of Smart Farming. Front. Sustain. Food Syst. 2018, 2. [CrossRef]

12. Walter, A.; Finger, R.; Huber, R.; Buchmann, N. Opinion: Smart farming is key to developing sustainable agriculture. Proc. Natl. Acad. Sci. USA 2017, 114, 6148. [CrossRef]

13. Bacco, M.; Berton, A.; Ferro, E.; Gennaro, C.; Gotta, A.; Matteoli, S.; Paonessa, F.; Ruggeri, M.; Virone, G.; Zanella, A. Smart farming: Opportunities, challenges and technology enablers. In Proceedings of the 2018 IoT Vertical and Topical Summit on Agriculture-Tuscany (IOT Tuscany), Tuscany, Italy, 8-9 May 2018; pp. 1-6.

14. Bacco, M.; Barsocchi, P.; Ferro, E.; Gotta, A.; Ruggeri, M. The Digitisation of Agriculture: A Survey of Research Activities on Smart Farming. Array 2019, 3-4, 100009. [CrossRef]

15. Nawar, S.; Corstanje, R.; Halcro, G.; Mulla, D.; Mouazen, A.M. Chapter Four-Delineation of Soil Management Zones for Variable-Rate Fertilization: A Review. In Advances in Agronomy; Sparks, D.L., Ed.; Academic Press: Cambridge, MA, USA, 2017; Volume 143, pp. 175-245.

16. Alameen, A.A.; Al-Gaadi, K.A.; Tola, E. Development and performance evaluation of a control system for variable rate granular fertilizer application. Comput. Electron. Agric. 2019, 160, 31-39. [CrossRef]

17. Stamatiadis, S.; Schepers, J.S.; Evangelou, E.; Glampedakis, A.; Glampedakis, M.; Dercas, N.; Tsadilas, C.; Tserlikakis, N.; Tsadila, E. Variable-rate application of high spatial resolution can improve cotton N-use efficiency and profitability. Precis. Agric. 2020, 21, 695-712. [CrossRef]

18. Boursianis, A.D.; Papadopoulou, M.S.; Diamantoulakis, P.; Liopa-Tsakalidi, A.; Barouchas, P.; Salahas, G.; Karagiannidis, G.; Wan, S.; Goudos, S.K. Internet of Things (IoT) and Agricultural Unmanned Aerial Vehicles (UAVs) in Smart Farming: A Comprehensive Review. Internet Things 2020, 100187. [CrossRef]

19. Muangprathub, J.; Boonnam, N.; Kajornkasirat, S.; Lekbangpong, N.; Wanichsombat, A.; Nillaor, P. IoT and agriculture data analysis for smart farm. Comput. Electron. Agric. 2019, 156, 467-474. [CrossRef]

20. Falco, G.; Nicola, M.; Pini, M.; Marucco, G.; Wilde, W.D.; Popugaev, A.; Gay, P.; Aimonino, D.R. Investigation of performance of GNSS-based devices for precise positioning in harsh agriculture environments. In Proceedings of the 2019 IEEE International Workshop on Metrology for Agriculture and Forestry (MetroAgriFor), Portici, Italy, 24-26 October 2019; pp. 1-6.

21. Stombaugh, T. Satellite-based Positioning Systems for Precision Agriculture. In Precision Agriculture Basics; American Society of Agronomy; Crop Science Society of America; Soil Science Society of America: Madison, WI, USA, 2018; pp. 25-36. 
22. Kamilaris, A.; Kartakoullis, A.; Prenafeta-Boldú, F.X. A review on the practice of big data analysis in agriculture. Comput. Electron. Agric. 2017, 143, 23-37. [CrossRef]

23. Bronson, K.; Knezevic, I. Big Data in food and agriculture. Big Data Soc. 2016, 3. [CrossRef]

24. Wolfert, S.; Ge, L.; Verdouw, C.; Bogaardt, M.-J. Big Data in Smart Farming-A review. Agric. Syst. 2017, 153, 69-80. [CrossRef]

25. Tsouros, C.D.; Bibi, S.; Sarigiannidis, G.P. A Review on UAV-Based Applications for Precision Agriculture. Information 2019, 10, 349. [CrossRef]

26. Hajjaj, S.S.H.; Sahari, K.S.M. Review of agriculture robotics: Practicality and feasibility. In Proceedings of the 2016 IEEE International Symposium on Robotics and Intelligent Sensors (IRIS), Tokyo, Japan, 17-20 December 2016; pp. 194-198.

27. Marinoudi, V.; Sørensen, C.G.; Pearson, S.; Bochtis, D. Robotics and labour in agriculture. A context consideration. Biosyst. Eng. 2019, 184, 111-121. [CrossRef]

28. Balafoutis, A.T.; Beck, B.; Fountas, S.; Tsiropoulos, Z.; Vangeyte, J.; van der Wal, T.; Soto-Embodas, I.; Gómez-Barbero, M.; Pedersen, S.M. Smart Farming Technologies-Description, Taxonomy and Economic Impact. In Precision Agriculture: Technology and Economic Perspectives; Pedersen, S.M., Lind, K.M., Eds.; Springer International Publishing: Cham, Switzerland, 2017; pp. 21-77.

29. Kernecker, M.; Knierim, A.; Wurbs, A.; Kraus, T.; Borges, F. Experience versus expectation: Farmers' perceptions of smart farming technologies for cropping systems across Europe. Precis. Agric. 2020, 21, 34-50. [CrossRef]

30. Lewis, T. Evolution of farm management information systems. Comput. Electron. Agric. 1998, 19, $233-248$. [CrossRef]

31. Kitchen, N.R. Emerging technologies for real-time and integrated agriculture decisions. Comput. Electron. Agric. 2008, 61, 1-3. [CrossRef]

32. Kaloxylos, A.; Eigenmann, R.; Teye, F.; Politopoulou, Z.; Wolfert, S.; Shrank, C.; Dillinger, M.; Lampropoulou, I.; Antoniou, E.; Pesonen, L.; et al. Farm management systems and the Future Internet era. Comput. Electron. Agric. 2012, 89, 130-144. [CrossRef]

33. Fountas, S.; Carli, G.; Sørensen, C.G.; Tsiropoulos, Z.; Cavalaris, C.; Vatsanidou, A.; Liakos, B.; Canavari, M.; Wiebensohn, J.; Tisserye, B. Farm management information systems: Current situation and future perspectives. Comput. Electron. Agric. 2015, 115, 40-50. [CrossRef]

34. Finger, R.; Swinton, S.M.; El Benni, N.; Walter, A. Precision Farming at the Nexus of Agricultural Production and the Environment. Annu. Rev. Resour. Econ. 2019, 11, 313-335. [CrossRef]

35. Zhang, N.; Wang, M.; Wang, N. Precision agriculture-A worldwide overview. Comput. Electron. Agric. 2002, 36, 113-132. [CrossRef]

36. Schellberg, J.; Hill, M.J.; Gerhards, R.; Rothmund, M.; Braun, M. Precision agriculture on grassland: Applications, perspectives and constraints. Eur. J. Agron. 2008, 29, 59-71. [CrossRef]

37. Balafoutis, A.; Beck, B.; Fountas, S.; Vangeyte, J.; Wal, T.V.D.; Soto, I.; Gómez-Barbero, M.; Barnes, A.; Eory, V. Precision Agriculture Technologies Positively Contributing to GHG Emissions Mitigation, Farm Productivity and Economics. Sustainability 2017, 9, 1339. [CrossRef]

38. Ge, Y.; Thomasson, J.A.; Sui, R. Remote sensing of soil properties in precision agriculture: A review. Front. Earth Sci. 2011, 5, 229-238. [CrossRef]

39. Brisco, B.; Brown, R.J.; Hirose, T.; McNairn, H.; Staenz, K. Precision Agriculture and the Role of Remote Sensing: A Review. Can. J. Remote Sens. 1998, 24, 315-327. [CrossRef]

40. Thorp, K.R.; Tian, L.F. A Review on Remote Sensing of Weeds in Agriculture. Precis. Agric. 2004, 5, 477-508. [CrossRef]

41. Zhang, C.; Kovacs, J.M. The application of small unmanned aerial systems for precision agriculture: A review. Precis. Agric. 2012, 13, 693-712. [CrossRef]

42. Abdullahi, H.S.; Mahieddine, F.; Sheriff, R.E. Technology Impact on Agricultural Productivity: A Review of Precision Agriculture Using Unmanned Aerial Vehicles. In Wireless and Satellite Systems, Proceedings of the 7th International Conference, WiSATS 2015, Bradford, UK, 6-7 July 2015; Pillai, P., Hu, Y.F., Otung, I., Giambene, G., Eds.; Springer International Publishing: Cham, Switzerland, 2015; pp. 388-400.

43. Mogili, U.M.R.; Deepak, B.B.V.L. Review on Application of Drone Systems in Precision Agriculture. Procedia Comput. Sci. 2018, 133, 502-509. [CrossRef] 
44. Reyns, P.; Missotten, B.; Ramon, H.; De Baerdemaeker, J. A Review of Combine Sensors for Precision Farming. Precis. Agric. 2002, 3, 169-182. [CrossRef]

45. Awasthi, A.; Reddy, S.R.N. Monitoring for Precision Agriculture using Wireless Sensor Network-A review. Glob. J. Comput. Sci. Technol. 2013, 13. Available online: https://computerresearch.org/index.php/computer/ article/view/391 (accessed on 20 February 2020).

46. Jawad, M.H.; Nordin, R.; Gharghan, K.S.; Jawad, M.A.; Ismail, M. Energy-Efficient Wireless Sensor Networks for Precision Agriculture: A Review. Sensors 2017, 17, 1781. [CrossRef]

47. Nash, E.; Korduan, P.; Bill, R. Applications of open geospatial web services in precision agriculture: A review. Precis. Agric. 2009, 10, 546. [CrossRef]

48. Lindblom, J.; Lundström, C.; Ljung, M.; Jonsson, A. Promoting sustainable intensification in precision agriculture: Review of decision support systems development and strategies. Precis. Agric. 2017, 18, 309-331. [CrossRef]

49. Kuhlmann, F.; Brodersen, C. Information technology and farm management: Developments and perspectives. Comput. Electron. Agric. 2001, 30, 71-83. [CrossRef]

50. Chlingaryan, A.; Sukkarieh, S.; Whelan, B. Machine learning approaches for crop yield prediction and nitrogen status estimation in precision agriculture: A review. Comput. Electron. Agric. 2018, 151, 61-69. [CrossRef]

51. Behmann, J.; Mahlein, A.-K.; Rumpf, T.; Römer, C.; Plümer, L. A review of advanced machine learning methods for the detection of biotic stress in precision crop protection. Precis. Agric. 2015, 16, 239-260. [CrossRef]

52. Liakos, K.G.; Busato, P.; Moshou, D.; Pearson, S.; Bochtis, D. Machine Learning in Agriculture: A Review. Sensors 2018, 18, 2674. [CrossRef] [PubMed]

53. Patrício, D.I.; Rieder, R. Computer vision and artificial intelligence in precision agriculture for grain crops: A systematic review. Comput. Electron. Agric. 2018, 153, 69-81. [CrossRef]

54. Brosnan, T.; Sun, D.-W. Inspection and grading of agricultural and food products by computer vision systems-A review. Comput. Electron. Agric. 2002, 36, 193-213. [CrossRef]

55. Vázquez-Arellano, M.; Griepentrog, W.H.; Reiser, D.; Paraforos, S.D. 3-D Imaging Systems for Agricultural Applications-A Review. Sensors 2016, 16, 618. [CrossRef]

56. Mousazadeh, H. A technical review on navigation systems of agricultural autonomous off-road vehicles. J. Terramechanics 2013, 50, 211-232. [CrossRef]

57. Bergerman, M.; Billingsley, J.; Reid, J.; van Henten, E. Robotics in Agriculture and Forestry. In Springer Handbook of Robotics; Siciliano, B., Khatib, O., Eds.; Springer International Publishing: Cham, Switzerland, 2016; pp. 1463-1492.

58. Bechar, A.; Vigneault, C. Agricultural robots for field operations: Concepts and components. Biosyst. Eng. 2016, 149, 94-111. [CrossRef]

59. Bechar, A.; Vigneault, C. Agricultural robots for field operations. Part 2: Operations and systems. Biosyst. Eng. 2017, 153, 110-128. [CrossRef]

60. Slaughter, D.C.; Giles, D.K.; Downey, D. Autonomous robotic weed control systems: A review. Comput. Electron. Agric. 2008, 61, 63-78. [CrossRef]

61. Bac, C.W.; van Henten, E.J.; Hemming, J.; Edan, Y. Harvesting Robots for High-value Crops: State-of-the-art Review and Challenges Ahead. J. Field Robot. 2014, 31, 888-911. [CrossRef]

62. Erickson, B.; Lowenberg-DeBoer, J. 2019 Precision Agriculture Dealership Survey: More Moves Toward Decision Agriculture. Available online: https:/www.croplife.com/management/2019-precision-agriculturedealership-survey-more-moves-toward-decision-agriculture/ (accessed on 18 March 2020).

63. Barnes, A.P.; Soto, I.; Eory, V.; Beck, B.; Balafoutis, A.; Sánchez, B.; Vangeyte, J.; Fountas, S.; van der Wal, T.; Gómez-Barbero, M. Exploring the adoption of precision agricultural technologies: A cross regional study of EU farmers. Land Use Policy 2019, 80, 163-174. [CrossRef]

64. Barnes, A.P.; Soto, I.; Eory, V.; Beck, B.; Balafoutis, A.T.; Sanchez, B.; Vangeyte, J.; Fountas, S.; van der Wal, T.; Gómez-Barbero, M. Influencing incentives for precision agricultural technologies within European arable farming systems. Environ. Sci. Policy 2019, 93, 66-74. [CrossRef]

65. Schieffer, J.; Dillon, C. The economic and environmental impacts of precision agriculture and interactions with agro-environmental policy. Precis. Agric. 2015, 16, 46-61. [CrossRef] 
66. Von Ahlefeld, P.J.W. Rebound effects in precision agriculture-A commentary. Ber. Über Landwirtsch. Z. Für Agrar. Und Landwirtsch. 2019. [CrossRef]

67. Paul, C.; Techen, A.-K.; Robinson, J.S.; Helming, K. Rebound effects in agricultural land and soil management: Review and analytical framework. J. Clean. Prod. 2019, 227, 1054-1067. [CrossRef]

68. Pretty, J.; Smith, G.; Goulding, K.W.T.; Groves, S.J.; Henderson, I.; Hine, R.E.; King, V.; van Oostrum, J.; Pendlington, D.J.; Vis, J.K.; et al. Multi-year assessment of Unilever's progress towards agricultural sustainability I: Indicators, methodology and pilot farm results. Int. J. Agric. Sustain. 2008, 6, 37-62. [CrossRef]

69. Walter, C.; Stützel, H. A new method for assessing the sustainability of land-use systems (I): Identifying the relevant issues. Ecol. Econ. 2009, 68, 1275-1287. [CrossRef]

70. Bockstaller, C.; Guichard, L.; Makowski, D.; Aveline, A.; Girardin, P.; Plantureux, S. Agri-environmental indicators to assess cropping and farming systems. A review. Agron. Sustain. Dev. 2008, 28, 139-149. [CrossRef]

71. European Environment Agency. Digest of EEA Indicators 2014; EEA Technical Report No. 8/2014; European Environment Agency: København, Denmark, 2014.

72. OECD. OECD Compendium of Agri-Environmental Indicators; OECD Publishing: Paris, France, 2013.

73. The Sustainability Consortium. Available online: https://www.sustainabilityconsortium.org/ (accessed on 28 March 2020).

74. Global Reporting Initiative. Available online: https://www.globalreporting.org (accessed on 28 March 2020).

75. Food and Agriculture Organisation of the United Nations. Productivity and Efficiency Measurement in Agriculture. Available online: https://www.fao.org/3/ca6428en/ca6428en.pdf (accessed on 22 February 2020).

76. United Nations. Glossary of Terms for Use with UNECE Standards on Fresh Fruit and Vegetables. 2016. Available online: https://www.unece.org/fileadmin/DAM/trade/agr/standard/fresh/StandardLayout/ Glossary_FFV_2016_E.pdf (accessed on 22 February 2020).

77. Wikipedia. Available online: https://en.wikipedia.org/wiki/Revenue (accessed on 22 February 2020).

78. European Commission. Overview of the Agricultural Input Sector in the EU. Available online: https: //www.europarl.europa.eu/RegData/etudes/STUD/2015/563385/IPOL_STU(2015)563385_EN.pdf (accessed on 22 February 2020).

79. Investing Answers. Available online: https://investinganswers.com/dictionary/v/variable-costs (accessed on 22 February 2020).

80. Food and Agriculture Organisation of the United Nations. Food Loss and Food Waste. Available online: www.fao.org/food-loss-and-food-waste/en/ (accessed on 22 February 2020).

81. Cambridge Dictionary. Available online: https://dictionary.cambridge.org/dictionary/english/energy-usage (accessed on 22 February 2020).

82. European Soil Data Centre. Joint Research Centre. Available online: https://esdac.jrc.ec.europa.eu/themes/ soil-biodiversity (accessed on 22 February 2020).

83. Cambridge Dictionary. Available online: https://dictionary.cambridge.org/dictionary/english/biodiversity (accessed on 22 February 2020).

84. Food and Agriculture Organisation of the United Nations. Fertiliser and Plant Nutrition Bulletin 6. Available online: http://www.fao.org/3/aq352e/aq352e.pdf (accessed on 22 February 2020).

85. European Commission. Pesticide Residues. Available online: https://ec.europa.eu/assets/sante/food/plants/ pesticides/lop/index.html (accessed on 22 February 2020).

86. United States Geological Survey. Available online: https://www.usgs.gov/mission-areas/water-resources/ science/irrigation-water-use?qt-science_center_objects=0\#qt-science_center_objects (accessed on 22 February 2020).

87. Food and Agriculture Organisation of the United Nations. Estimating Greenhouse Gas Emissions in Agriculture. Available online: http://www.fao.org/3/a-i4260e.pdf (accessed on 22 February 2020).

88. Buijsman, E.; Maas, H.F.M.; Asman, W.A.H. Anthropogenic NH3 emissions in Europe. Atmos. Environ. 1987, 21, 1009-1022. [CrossRef]

89. Oenema, O.; Boers, P.C.M.; van Eerdt, M.M.; Fraters, B.; van der Meer, H.G.; Roest, C.W.J.; Schröder, J.J.; Willems, W.J. Leaching of nitrate from agriculture to groundwater: The effect of policies and measures in the Netherlands. Environ. Pollut. 1998, 102, 471-478. [CrossRef] 
90. IUPAC Goldbook. Available online: https://goldbook.iupac.org/terms/view/P04520 (accessed on 22 February 2020).

91. Sustainable Agriculture Research and Education. Available online: https://www.sare.org/Learning-Center/ Bulletins/A-Whole-Farm-Approach-to-Managing-Pests/Text-Version/Reducing-Pest-Pressure (accessed on 22 February 2020).

92. Lexico. Available online: https://www.lexico.com/definition/labour_time (accessed on 22 February 2020).

93. Health and Safety Executive UK. Available online: https://www.hse.gov.uk/research/rrpdf/rr362.pdf (accessed on 22 February 2020).

94. Cambridge Dictionary. Available online: https://dictionary.cambridge.org/dictionary/english/labour (accessed on 22 February 2020).

95. Safeopedia. Available online: https:/www.safeopedia.com/definition/1237/work-related-injury (accessed on 22 February 2020).

96. Wikipedia. Available online: https://en.wikipedia.org/wiki/Work_accident (accessed on 22 February 2020).

97. European Commission CORDIS Online Database. Available online: https://cordis.europa.eu/ (accessed on 18 March 2020).

98. Agricultural European Innovation Platform (EIP-Agri). Available online: https:/ec.europa.eu/eip/agriculture/ en/eip-agri-common-format (accessed on 18 March 2020).

99. Technology Readiness Levels (TRL) Definition. Available online: https://ec.europa.eu/research/participants/ data/ref/h2020/wp/2014_2015/annexes/h2020-wp1415-annex-g-trl_en.pdf (accessed on 13 January 2020).

100. Technology Readiness Level (TRL) Calculator Version 2.2 Developed by the Air Force Research Laboratory (AFRL). Available online: https://www.dau.edu/cop/stm/Lists/Tools/DispForm.aspx?ID=4\&Source=https $\%$

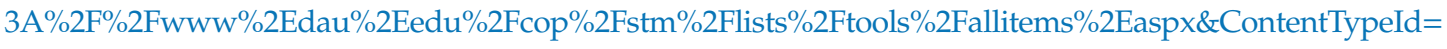
0x010051CD3A8A368D5347A6595B3B5385510700AA867A0513EB0A44B7EC5897985C3BB8 (accessed on 10 January 2020).

101. Schwarz, J.; Herold, L. Typology of PF Technologies; FP7 Project Future Farm; European Commission: Brussels, Belgium, 2011.

102. Rogers, E.M. Diffusion of Innovations, 4th ed.; The Free Press: New York, NY, USA, 1995; p. 519.

103. Merfield, C.N. Robotic weeding's false dawn? Ten requirements for fully autonomous mechanical weed management. Weed Res. 2016, 56, 340-344. [CrossRef]

104. Khan, N.; Medlock, G.; Graves, S.; Anwar, S. GPS Guided Autonomous Navigation of a Small Agricultural Robot with Automated Fertilizing System; SAE Technical Paper 2018-01-0031; 2018. [CrossRef]

105. Normile, M.A.; Leetmaa, S.E. U.S.-EU Food and Agriculture Comparisons; Agriculture and Trade Report; U.S. Department of Agriculture: Washington, DC, USA, 2004.

106. Baillie, C.P.; Lobsey, C.R.; Antille, D.L.; McCarthy, C.L.; Thomasson, J.A. A review of the state of the art in agricultural automation. Part III: Agricultural machinery navigation systems. In Proceedings of the 2018 ASABE Annual International Meeting, Detroit, MI, USA, 29 July-1 August 2018; ASABE: St. Joseph, MI, USA; p. 1.

107. Diacono, M.; Rubino, P.; Montemurro, F. Precision nitrogen management of wheat. A review. Agron. Sustain. Dev. 2013, 33, 219-241. [CrossRef]

108. Chen, C.; Pan, J.; Lam, S.K. A review of precision fertilization research. Environ. Earth Sci. 2014, 71, 4073-4080. [CrossRef]

109. Weis, M.; Gutjahr, C.; Rueda Ayala, V.; Gerhards, R.; Ritter, C.; Schölderle, F. Precision farming for weed management: Techniques. Gesunde Pflanz. 2008, 60, 171-181. [CrossRef]

110. Song, Y.; Sun, H.; Li, M.; Zhang, Q. Technology Application of Smart Spray in Agriculture: A Review. Intell. Autom. Soft Comput. 2015, 21, 319-333. [CrossRef]

111. Neupane, J.; Guo, W. Agronomic Basis and Strategies for Precision Water Management: A Review. Agronomy 2019, 9, 87. [CrossRef]

112. Pereira, C.S.; Morais, R.; Reis, M.J.C.S. Recent advances in image processing techniques for automated harvesting purposes: A review. In Proceedings of the 2017 Intelligent Systems Conference (IntelliSys), London, UK, 7-8 September 2017; pp. 566-575. 
113. Soto, I.; Barnes, A.; Balafoutis, A.; Beck, B.; Sanchez, B.; Vangeyte, J.; Fountas, S.; Wal, T.V.D.; Eory, V.; Gómez-Barbero, M. The Contribution of Precision Agriculture Technologies to Farm Productivity and the Mitigation of Greenhouse Gas Emissions in the EU; EU Science Hub. Publications Office of the European Union: Brussels, Belgium, 2019; ISBN 978-92-79-92834-5. ISSN 1831-9424. [CrossRef]

114. Pedersen, S.M.; Lind, K.M. Precision Agriculture-From Mapping to Site-Specific Application. In Precision Agriculture: Technology and Economic Perspectives; Pedersen, S.M., Lind, K.M., Eds.; Springer International Publishing: Cham, Switzerland, 2017; pp. 1-20.

115. Mouazen, A.M.; Alexandridis, T.; Buddenbaum, H.; Cohen, Y.; Moshou, D.; Mulla, D.; Nawar, S.; Sudduth, K.A. Chapter 2-Monitoring. In Agricultural Internet of Things and Decision Support for Precision Smart Farming; Castrignanò, A., Buttafuoco, G., Khosla, R., Mouazen, A.M., Moshou, D., Naud, O., Eds.; Academic Press: Cambridge, MA, USA, 2020; pp. 35-138.

116. Kay, N.M.; Leih, S.; Teece, D.J. The role of emergence in dynamic capabilities: A restatement of the framework and some possibilities for future research. Ind. Corp. Chang. 2018, 27, 623-638. [CrossRef]

117. Teece, D.J. Profiting from innovation in the digital economy: Enabling technologies, standards, and licensing models in the wireless world. Res. Policy 2018, 47, 1367-1387. [CrossRef]

118. Bower, J.L.; Christensen, C.M. Disruptive technologies: Catching the wave. Harv. Bus. Rev. 1995, 73, 43-53.

119. Michels, M.; von Hobe, C.-F.; Musshoff, O. A trans-theoretical model for the adoption of drones by large-scale German farmers. J. Rural Stud. 2020, 75, 80-88. [CrossRef]

120. Drewry, J.L.; Shutske, J.M.; Trechter, D.; Luck, B.D.; Pitman, L. Assessment of digital technology adoption and access barriers among crop, dairy and livestock producers in Wisconsin. Comput. Electron. Agric. 2019, 165, 104960. [CrossRef]

121. Griliches, Z. Hybrid Corn and the Economics of Innovation. Science 1960, 132, 275. [CrossRef]

122. David, P. Zvi Griliches and the Economics of Technology Diffusion: Linking innovation adoption, lagged investments, and productivity growth. SIERP 2015, 15, 5. Available online: https://siepr.stanford.edu/sites/ default/files/publications/15-005_0.pdf (accessed on 20 February 2020).

123. Feder, G.; Slade, R. The Acquisition of Information and the Adoption of New Technology. Am. J. Agric. Econ. 1984, 66, 312-320. [CrossRef]

124. Genius, M.; Pantzios, C.J.; Tzouvelekas, V. Information Acquisition and Adoption of Organic Farming Practices. J. Agric. Resour. Econ. 2006, 31, 93-113.

125. Horizon 2020 Work Programme 2018-2020, European Commission Decision C (2019) 4575 of 2 July 2019. Available online: https:/ec.europa.eu/research/participants/data/ref/h2020/other/wp/2018-2020/annexes/ h2020-wp1820-annex-ga_en.pdf (accessed on 10 January 2020).

126. Pedersen, S.M.; Fountas, S.; Blackmore, B.S.; Gylling, M.; Pedersen, J.L. Adoption and perspectives of precision farming in Denmark. Acta Agric. Scand. Sect. B Soil Plant Sci. 2004, 54, 2-8. [CrossRef]

127. Jensen, H.G.; Jacobsen, L.-B.; Pedersen, S.M.; Tavella, E. Socioeconomic impact of widespread adoption of precision farming and controlled traffic systems in Denmark. Precis. Agric. 2012, 13, 661-677. [CrossRef]

128. Bongiovanni, R.; Lowenberg-Deboer, J. Economics of Variable Rate Lime in Indiana. Precis. Agric. 2000, 2, 55-70. [CrossRef]

129. Bongiovanni, R.; Lowenberg-Deboer, J. Precision Agriculture and Sustainability. Precis. Agric. 2004, 5, 359-387. [CrossRef]

130. Reddy, P.P. Precision Agriculture. In Agro-Ecological Approaches to Pest Management for Sustainable Agriculture; Reddy, P.P., Ed.; Springer: Singapore, 2017; pp. 295-309.

131. Erisman, J.W.; van Eekeren, N.; de Wit, J.; Koopmans, C.; Cuijpers, W.; Oerlemans, N.; Koks, B.J. Agriculture and biodiversity: A better balance benefits both. Aims Agric. Food 2016, 1, 157-174. [CrossRef]

132. Meyer-Aurich, A.; Gandorfer, M.; Heißenhuber, A. Economic analysis of precision farming technologies at the farm level: Two german case studies. In Agricultural Systems: Economics, Technology, Diversity; Castelonge, O.W., Ed.; Nova Science Publishers: Hauppage, NY, USA, 2008; pp. 67-76. ISBN 978-1-60692-025-1. 
133. Pedersen, S.M.; Fountas, S.; Have, H.; Blackmore, B.S. Agricultural robots-System analysis and economic feasibility. Precis. Agric. 2006, 7, 295-308. [CrossRef]

134. Batte, M.T. Precision Farming and Land Leasing Practices. J. Asfmra Am. Soc. Farm Manag. Rural Appraisers 2003, 2003, 55-63. Available online: http://ageconsearch.umn.edu/record/198075/files/200.pdf (accessed on 20 March 2020). article distributed under the terms and conditions of the Creative Commons Attribution (CC BY) license (http://creativecommons.org/licenses/by/4.0/). 